NBER WORKING PAPER SERIES

\title{
LAND SECURITY AND MOBILITY FRICTIONS
}

\author{
Tasso Adamopoulos \\ Loren Brandt \\ Chaoran Chen \\ Diego Restuccia \\ Xiaoyun Wei \\ Working Paper 29666 \\ http://www.nber.org/papers/w29666
NATIONAL BUREAU OF ECONOMIC RESEARCH
1050 Massachusetts Avenue
Cambridge, MA 02138
January 2022

We thank Lin Ma, Kjetil Storesletten, Xiaodong Zhu, and seminar participants at Academia Sinica, Boston University, the Midwest Macro Meeting at Michigan State University, the North American Meeting of the Econometric Society in Montreal, Peking University, Queen's University, the Society of Economic Dynamics in Minneapolis, Texas A\&M University, Trinity College Dublin, University of Nottingham. Adamopoulos, Brandt, and Chen gratefully acknowledge the support from the Social Sciences and Humanities Research Council of Canada. Brandt thanks the support from the Noranda Chair for International Trade and Economics. Restuccia gratefully acknowledges the support from the Canada Research Chairs program and the Bank of Canada Fellowship program. Funding from the Research Support Board at the World Bank supported data access and collection. The views expressed herein are not necessarily those of the Bank of Canada and are the authors alone. All errors are our own. The views expressed herein are those of the authors and do not necessarily reflect the views of the National Bureau of Economic Research.

NBER working papers are circulated for discussion and comment purposes. They have not been peer-reviewed or been subject to the review by the NBER Board of Directors that accompanies official NBER publications.

(C) 2022 by Tasso Adamopoulos, Loren Brandt, Chaoran Chen, Diego Restuccia, and Xiaoyun Wei. All rights reserved. Short sections of text, not to exceed two paragraphs, may be quoted without explicit permission provided that full credit, including $\odot$ notice, is given to the source. 
Land Security and Mobility Frictions

Tasso Adamopoulos, Loren Brandt, Chaoran Chen, Diego Restuccia, and Xiaoyun Wei NBER Working Paper No. 29666

January 2022

JEL No. E02,O11,O14,O4,Q1

\begin{abstract}
$\underline{\text { ABSTRACT }}$
Developing countries are characterized by frictions that impede the mobility of workers across occupations and space. We disentangle the role of insecure property rights from other labor mobility frictions for the reallocation of labor from agriculture to non-agriculture and from rural to urban areas. We combine rich household and individual-level panel data from China and an equilibrium quantitative framework that features the sorting of workers across locations and occupations. We explicitly model the farming household and the endogenous decisions of who operates the family farm and who potentially migrates, capturing an additional channel of selection within the household. We find that land insecurity has substantial negative effects on agricultural productivity and structural change, raising the share of households operating farms by almost 30 percentage points and depressing agricultural productivity by more than 10 percent. Quantitatively, land insecurity is as important as all other labor mobility frictions. We measure a sharp reduction in overall labor mobility barriers over 2004-2018 in the Chinese economy, all of which can be accounted for by improved land security, consistent with reforms covering rural land in China during the period.
\end{abstract}

Tasso Adamopoulos

York University

Canada

aadamo@yorku.ca

Loren Brandt

Department of Economics

University of Toronto

150 St. George Street

Toronto, ON M5S 3G7 CANADA

loren.brandt@utoronto.ca

Chaoran Chen

York University

4700 Keele St.

Toronto, ON M3J 1P3

Canada

chenecon@yorku.ca

\author{
Diego Restuccia \\ Department of Economics \\ University of Toronto \\ 150 St. George Street \\ Toronto, ON M5S 3G7 \\ CANADA \\ and NBER \\ diego.restuccia@utoronto.ca \\ Xiaoyun Wei \\ Shanghai Jiao Tong University \\ No. 1954, Huashan Road \\ Shanghai 200030 \\ China \\ xiaoyun_wei@sjtu.edu.cn
}




\section{Introduction}

The movement of workers from agriculture to non-agriculture and from rural to urban locations is fundamental to the process of structural transformation and economic development. In many developing and transition economies, explicit and implicit frictions impede the mobility of workers across occupations and space. These frictions can have important implications for sectoral and aggregate productivity as well as welfare. Disentangling their effects is key to understanding the drivers of productivity and prioritizing policy initiatives.

China is a country with well-documented migration restrictions that have been the focus of extensive research (Chan and Zhang, 1999; Tombe and Zhu, 2019; Caliendo et al., 2019). In addition, there are implicit mobility restrictions tied to insecure property rights over farmland (Ngai et al., 2019; Adamopoulos et al., 2021; Giles and Mu, 2018), frictions that have been identified as important in other contexts (de Janvry et al., 2015). The risk to farmers of losing their use rights over land if they do not farm it themselves may deter land rentals, work outside agriculture, and migration to urban areas. China offers a unique opportunity to assess the relative importance of alternative mobility frictions that are prevalent in the developing world.

In this paper, we combine rich individual- and household-level panel data for 2004-2018 and a structural model to quantify the importance of frictions arising from land insecurity and labor mobility restrictions for agricultural productivity and structural change. For 2004, we find that land insecurity constitutes a barrier to labor mobility that is almost as large as all residual labor mobility frictions in terms of their effect on farm employment and agricultural productivity. We also find that barriers to labor reallocation in China fall significantly by 2018, all of which can be attributed to improved land security as other labor mobility costs

actually rise slightly. The importance our analysis attaches to improved land security in facilitating labor mobility is consistent with institutional reforms affecting property rights in farmland, while efforts to relax other labor mobility barriers have stalled (Chan, 2019).

Our quantitative framework is motivated by three striking regularities in the micro data 
for China. First, despite rapid economic growth, urbanization, and structural change in China, we observe limited farm consolidation through the early 2000s. Operational farm sizes remained small, and averaged under 0.6 hectares in 2004. Second, farms were typically operated by older individuals within the household, with younger members more likely to seek employment opportunities outside farming. In 2004, individuals over the age of 45 represented $40.5 \%$ of the labor force in the countryside, but were operators of $57.8 \%$ percent of all farms. And third, of those working in non-agriculture, more than half were employed locally, with the rest migrating to the cities to work.

To account for the rich heterogeneity of individual and household choices in the micro data, we build a structural model populated by households with young and old members. Each individual can work in agriculture in the village or in non-agriculture, either locally or by migrating to the cities. Individuals may also choose to work part time in farming and non-agriculture. Household members are heterogeneous with respect to their ability in these occupations, which allows for selection across sectors and space. A novelty of our analysis is that we explicitly model the endogenous household decision of who operates the family farm and who migrates, thereby capturing an additional channel of selection within the household.

We allow for idiosyncratic distortions in household and individual choices. Rural households face two distortions related to weak property rights over land: First, a barrier to land reallocation within agriculture between farming households. Second, land insecurity, associated with the income drop from losing their use rights if the household does not farm the land itself, which captures a household's perception of land insecurity, a de-facto rather than de-jure measure. In addition, individual labor supply choices are subject to residual idiosyncratic occupational and spatial labor mobility frictions. These frictions are orthogonal to the perceived land insecurity frictions and are a catchall for all other institutions or frictions such as an individual's hukou and explicit migration costs, which may impede the mobility of workers out of agriculture and affect sorting.

Our framework gives rise to rich patterns of selection, within households, across occupa- 
tions, and across space, which have implications for agricultural and aggregate productivity and structural change. We quantitatively evaluate the role of land insecurity and other labor mobility frictions for these outcomes, exploiting rich micro-level data on individuals and households for China over 2004-2018. The data provide detailed information on labor supply, farm production, and incomes to which we calibrate our model. Observed incomes of individuals and the variation between and within families in sector and spatial choices allow us to identify empirically household perceived land insecurity and other labor mobility frictions at the individual level. Survey data we collected in China expressly for these purposes allow for more direct measures of household land insecurity.

We find that in 2004 labor mobility frictions associated with land insecurity are high in levels and large in dispersion and responsible for an inefficiently large number of farms in agricultural production. Moreover, the effects of land insecurity on employment and agricultural labor productivity are similar in magnitude to all other labor mobility frictions. Older workers also face substantially higher overall barriers to labor mobility compared to younger workers, which helps to explain why they are more likely to operate farms. From the perspective of 2004, introducing secure land rights substantially reduces the share of households operating farms from 72 percent to 43 percent and lowers the share of employment in agriculture among village households from 57 to 51 percemt, resulting in an improvement in agricultural productivity of 10.5 percent. By comparison, removing all other labor mobility frictions reduces the percentage of village households farming to 50 percent and increases agricultural productivity by 11.8 percent.

Over the period 2004-2018 we find a marked improvement in land security but a slight increase in other labor mobility frictions. Our analysis highlights that much of the increase in labor mobility over the period is tied to improvements in land tenure security, consistent with policy reforms pursued in China since the early 2000s. We also find an important interaction between land insecurity and misallocation within agriculture as the productivity gain from an efficient reallocation of resources within agriculture more than doubles when land is 
secure. These additional gains arise from improved selection in farming within households and improved selection across sectors and space. Finally, we find important village-level differences in labor mobility in China, with peri-urban areas facing less severe land insecurity and lower local labor mobility barriers than more remote areas.

Our paper relates to several strands of literature. In highlighting the role of farming for labor supply choices our work relates to the literature on structural transformation and agriculture (Gollin et al., 2002; Restuccia et al., 2008), and the agricultural productivity gap (Gollin et al., 2014). The paper is also connected to the agricultural productivity literature emphasizing misallocation (Adamopoulos and Restuccia, 2014), particularly that relating to land market institutions (Adamopoulos and Restuccia, 2020; Chen, 2017; Gottlieb and Grobovšek, 2019; Adamopoulos et al., 2021; Chari et al., 2021), and sectoral selection (Lagakos and Waugh, 2013; Adamopoulos et al., 2021; Alvarez, 2020; Hamory et al., 2021). Equally related is the literature on migration costs and structural transformation (Morten and Oliveira, 2018; Bryan and Morten, 2019; Lagakos et al., 2020; Schoellman, 2020; Hamory et al., 2021). ${ }^{1}$ While these papers focus on estimating the magnitude of migration costs using reduced-form or structural approaches, we aim to disentangle the implicit migration cost arising from insecure land rights from other labor mobility barriers. Our paper is also broadly related to the literature on growth and development in the context of China (Song et al., 2011; Brandt et al., 2013, 2020, among others) and the literature on institutions as an obstacle to development in poor countries (Acemoglu et al., 2001, 2005).

The two papers most closely related to ours are Ngai et al. (2019) and Adamopoulos et al. (2021). Ngai et al. (2019) highlight that land insecurity can manifest as a labor mobility barrier out of agriculture in China. We use micro-level data to estimate heterogeneous land insecurity and other labor mobility barriers, and quantitatively assess their contribution for aggregate productivity and structural change, allowing in addition for selection. Quantita-

\footnotetext{
${ }^{1}$ The literature has studied several factors that could deter labor mobility, including transportation infrastructure (Asher and Novosad, 2020); land use rights (de Janvry et al., 2015); rural insurance networks (Munshi and Rosenzweig, 2016); monetary cost and risk (Bryan et al., 2014); administrative registration and services (Chan and Zhang, 1999); housing (Brueckner and Lall, 2015).
} 
tively, selection turns out to account for the largest component of these effects. Adamopoulos et al. (2021) highlight the effect of China's land institutions for misallocation within villages in agriculture and sectoral selection using household-level data for an earlier period. In contrast, we use individual- and household-level data to estimate idiosyncratic mobility barriers and study labor allocation and migration decisions within households, thus allowing us to examine misallocation within households and across space. Relative to the previous literature, we also model differences between young and old cohorts in their ability and mobility barriers to capture the phenomenon of structural transformation by cohorts (Hobijn et al., 2018).

The paper proceeds as follows. The next section describes the land and labor mobility institutions in China. Section 3 documents key regularities on China's structural transformation that motivate our framework of analysis. In Section 4, we present the model and section 5 estimates the model by matching moments from micro and aggregate data for 2004 . Section 6 performs quantitative experiments in order to assess the relevance of land security and other mobility frictions and their evolution over time. We also evaluate the interaction of land insecurity and farm-level distortions associated with China's land institution. In section 7 , we provide alternative empirical estimates of the cost of land insecurity and assess regional heterogeneity. We conclude in section 8.

\section{Institutional Background}

Our framework decomposes the costs associated with the out-migration of workers from agriculture into those related to land market institutions and all other labor mobility frictions. In this section, we provide institutional context for land and labor mobility policies in China.

Land market institutions. With the introduction of the Household Responsibility System in the early 1980s, rural households were granted use rights and residual income rights over land. Farmland was not privatized however, and ownership continued to reside in the 
collective, i.e. village. The allocation of village land was highly egalitarian, and tied to "membership" in the village through the household registration system. As a result, per capita differences between households in landholdings within a village were small.

Initially, use rights were extended to households for 15 years. Through the late 1990s however local officials often carried out village-wide reallocations of land between households to accommodate demographic changes (Benjamin and Brandt, 2002). ${ }^{2}$ In addition, rural land was occasionally expropriated from households by the state for non-agricultural uses including highway construction, urban development, and industrial parks.

In most villages, land rental was not officially restricted, however rental markets were thin, with less than 3 percent of total land rented out by the mid-1990s (Brandt et al., 2002). "Use-it-or-lose-it rules" were likely partially responsible. Village leaders often regarded rental transactions as a signal of land misallocation, and viewed village land reallocations as an opportunity to redirect farmland to other households. Since rentals invited dispossession, households were unwilling to rent out their land.

This incomplete set of property rights over land had two important implications. First, land was misallocated within villages, a product of the highly egalitarian distribution of use rights and limited market-based reallocation through rental. And second, fear of the loss of land use rights (or compensation in the event of expropriation) prompted households to assign family members to farm the land to protect their rights.

A series of reforms to land policy in China beginning in the late 1990s helped to strengthen household property rights, but did not privatize farmland. In 1998, the Land Management Law (LML) extended the use rights to rural households for 30 years. In 2003, the Rural Land Contracting Law (RLCL) codified legal rights of rural households for leasing out agricultural land. Estimates suggest that this reform led to a 7 percent increase in land rentals, and the reallocation of land towards higher productivity households (Chari et al., 2021). In 2013, further reform to land policy allowed farmers to transfer their land use rights to

\footnotetext{
${ }^{2}$ Rent-seeking behavior on the part of village leaders was also likely a factor (Brandt et al., 2002; Kung and Liu, 1997).
} 
others, including large commercial farms. In 2014, the right to mortgage the use of land was also extended to rural households (Zhou et al., 2021). Finally, in 2018, a formal land titling/certification process was begun that by 2021 was largely complete.

Labor mobility institutions. Labor mobility in China has been heavily influenced by the Household Registration or Hukou System (Chan, 2019). Established in the 1950s, the primary purpose of the system was to control migration between the countryside and the cities. Under the hukou system, each individual is assigned agricultural or non-agricultural hukou within a locality, e.g. village, town or city, which determines where they can live and work, and their rights and access to local public services. Major differences exist between rural and urban areas in the level and availability of these services, as well as between cities since larger cities typically confer much better benefits than smaller cities.

Through the late 1970s there were very tight restrictions on migration, as well as on the type of non-agricultural activities that were permitted in the countryside. Restrictions on the type of activity began to be relaxed in the early $1980 \mathrm{~s}$, followed by an easing of restrictions on rural hukou holders from moving to the cities to work (de Brauw and Giles, 2018). Rural migrants continued to be restricted however in terms of the public services they could access once they moved. Data from China's population census reveal that migrants' share of non-agricultural employment rose from 6.4 in 1990 to 17.7 percent 2000, and then to 21.0 percent in 2005 .

In the early 2000s, new reforms made it easier for migrant workers to obtain working permits in other provinces, with some coastal provinces totally eliminating the requirement. In 2014, the distinction between agricultural and non-agricultural hukou in the same location was eliminated, thereby entitling, on paper, all residents to the same set of local public services. Chan (2019) argues however that this reform was primarily limited to smaller cities, and that it actually became harder to obtain local hukou in larger coastal cities, which restricted in-migration and even tried to force migrants out by limiting migrants' 
children access to education. Rising housing prices in the cities likely reinforced the effects of weak enforcement of reforms, and contributed to rising migration costs for rural families.

Data from the Population Census for 2005, 2010 and 2015 reveal a slowing in labor flows, with migrants' share of non-agricultural employment rising to 26.5 percent in 2010 , but to only 28.3 percent by 2015. Consistent with these trends, Wu and You (2020) find that the probability of migrants obtaining local hukou also experienced a pronounced reduction over the same period. For individuals that had completed high school, for example, the probability of receiving urban hukou within 5 years fell from 16.3 and 38.6 percent in tier 1 and 2 cities in 2000, respectively, to only 3.9 and 10.5 percent in 2010.

\section{Stylized Facts on China's Structural Transformation}

The Chinese economy has experienced significant structural change that has been accompanied by a marked reduction in the share of the labor force engaged in agriculture. Between 1995 and 2018, the share dropped from 48.0 percent to 15.5 percent. This decline reflects two forces: The increase in the percentage of households living and working in the cities, and changes in the employment patterns of households registered in the countryside.

We draw on the nationally-representative rural household survey data collected by the Research Center for the Rural Economy (RCRE) under the Ministry of Agriculture of China to describe salient features of the changes in the countryside that motivate our framework and analysis. ${ }^{3}$ We focus on the period between 2004 and 2018, leveraging the individual-level labor supply data that were added to the survey in 2003. Our unbalanced panel contains information on over 20,000 households per year, drawn from 300 villages.

Agricultural employment. The first row of Table 1 reports the falling share of China's total labor force employed in agriculture between 2004 and 2018. This decline reflects two forces: The reduction in the share of households registered in rural areas, which fell from

\footnotetext{
${ }^{3}$ For a detailed earlier description of the data see Benjamin et al. (2005).
} 
$68.7 \%$ in 2004 to $41.6 \%$ in 2018, and the reallocation of labor from agriculture to nonagriculture among rural residents. ${ }^{4}$ Among those registered in the countryside, the share working in agriculture fell from 70.7 to 48.4 percent. The largest reductions occurred among full-time farm operators and part-time workers, which fell 10.5 and 7.6 percentage points, respectively. Other household members working full time in agriculture fell 4.1 percentage points. A simple decomposition suggests that the reallocation of labor among rural residents from agriculture to non-agriculture was the source of half of the total reduction in the nationwide share of employment in agriculture.

Table 1: Employment in Agriculture

\begin{tabular}{lcccc}
\hline Variable & 2004 & 2009 & 2014 & 2018 \\
\hline Nationwide agricultural employment share (\%) & 39.1 & 28.4 & 19.8 & 15.5 \\
$\begin{array}{l}\text { Share of all households living in rural area (\%) } \\
\text { Share of labor days in agriculture }\end{array}$ & 68.7 & 56.3 & 45.6 & 41.6 \\
$\quad$ & 56.9 & 50.4 & 43.2 & 37.8 \\
\hline among rural households (\%) & & & & \\
Share of individuals in rural areas & 70.7 & 63.9 & 56.2 & 48.4 \\
$\quad$ involved in agriculture (\%) & 27.0 & 23.1 & 19.6 & 16.5 \\
$\quad$ Share of farm operators (\%) & 22.3 & 21.3 & 18.8 & 18.2 \\
$\quad$ Share of full-time workers (\%) & 21.3 & 19.5 & 17.8 & 13.7 \\
$\quad$ Share of part-time workers (\%) & & & &
\end{tabular}

Notes: Nationwide statistics adjusted from the Chinese Statistics Yearbook. All other statistics are calculated from micro-level data from the RCRE survey, as shares out of the total numbers of employed individuals in the survey. For each year the shares of farm operators, full-time and part-time workers sum up to the total share in agriculture, save for rounding.

Status and location of non-agricultural work. In Table 2, we document the accompanying changes in the level and composition of non-agricultural employment among rural households. We distinguish between individuals working full and part-time in nonagriculture, and between those working in urban versus rural locations. In 2004, 50.6\% of individuals were employed in non-agriculture, of which $29.3 \%$ were full-time, and $21.3 \%$ were part-time. Between 2004 and 2018, the percentage of individuals working in non-agriculture

\footnotetext{
${ }^{4}$ In each year, the share of nationwide employment in agriculture is the product of the share of households living in rural areas and the share of labor among these households in agriculture.
} 
increased from 50.6 percent to 65.3 percent of the labor force. Much of this increase is a product of the growth in full-time employment in non-agriculture, which grew from 29.3 percent to 51.6 percent; the share working part-time fell from 21.3 percent to 13.7 percent (rows one and four of Table 2). A key feature of China's development has been the important role of non-agricultural employment opportunities in the countryside. Over time however, we see a slight shift in the percentage working in the cities, which increases from 40 percent to 45 percent. Accompanying this rise is the reduction in the role of part-time non-agriculture employment in rural areas.

Table 2: Status and Location of Non-Agricultural Work

\begin{tabular}{lcccc}
\hline Variable & 2004 & 2009 & 2014 & 2018 \\
\hline Full-time non-agriculture (\%) & 29.3 & 36.1 & 43.8 & 51.6 \\
Rural (\%) & 14.6 & 16.3 & 21.6 & 25.9 \\
Urban (\%) & 14.8 & 19.8 & 22.2 & 25.7 \\
Part-time non-agriculture (\%) & 21.3 & 19.5 & 17.8 & 13.7 \\
Rural (\%) & 16.0 & 14.4 & 12.8 & 9.8 \\
Urban (\%) & 5.3 & 5.1 & 5.0 & 3.9 \\
\hline
\end{tabular}

Notes: All statistics are calculated from micro-level data from the RCRE survey, as shares out of the total numbers of employed individuals in the survey. For each year the shares of rural and urban workers sum up to the total share in non-agriculture by full- and part-time status.

Labor supply by age cohort. The labor supply of individuals across sectors differs considerably between age cohorts. We divide workers into "young" and "old", using 45 years of age as the cutoff. As reported in Table 3, in 2004, 57.8 percent of farm operators and 51.2 percent of full-time agricultural workers are old. By 2018, the share of the "old" in these two groups increased to 80.0 and 71.8 percent, respectively. These patterns partly reflect the aging of the Chinese population and the overall rise in the number that are old. Between 2004 and 2018, the old rise as a share of the labor force from $40.5 \%$ to $52.4 \%$.

In Table 4, we provide separate breakdowns of labor supply in agriculture among the old (Panel A), and the young (Panel B). Overall, the share of the old engaged in agricultural activities is consistently higher than the share of young. In 2004, 86 percent of the old were 
engaged in agricultural activities compared to 60 percent of the young. However, the pace of structural change in employment differs significantly between the two cohorts. By 2018, the share of old engaged in agriculture dropped a quarter to 66 percent, while that of the young fell to less than half of its 2004 level, or 29 percent. Among the old working in agriculture in 2004, farm operators is the largest group. Most of the reduction in the share of the old working in agriculture is due to the decline in farm operators; the shares of the old working either full- or part-time in farming fall only modestly. In contrast, in 2004, most of the young are involved in agriculture as either full-time or part-time workers. However, the reduction in the young in farming is distributed far more evenly among farm operators and workers than in the case of the old.

Table 3: Share of Old Cohort by Employment Types

\begin{tabular}{lcccc}
\hline Variable & 2004 & 2009 & 2014 & 2018 \\
\hline Population (\%) & 40.5 & 43.4 & 49.0 & 52.4 \\
Agriculture (\%) & 49.2 & 55.5 & 64.9 & 71.5 \\
Farm operators (\%) & 57.8 & 66.2 & 75.9 & 80.5 \\
Full-time workers (\%) & 51.2 & 57.1 & 65.4 & 71.8 \\
Part-time workers (\%) & 36.2 & 41.2 & 52.2 & 60.2 \\
\hline
\end{tabular}

Notes: All statistics are calculated from micro-level data from the RCRE survey, as shares of old cohorts among all individuals working in each occupation category. The share of old cohort within agriculture is the weighted average of the share of old cohorts among farm operators, that among full-time agricultural workers, and that among part-time agricultural workers, where the weight is the share of individuals falling into these categories of occupations.

Average farm size and land rentals. In Table 5 we report for select years average farm size of farming households in the RCRE survey, measured as total cultivated area divided by the number of farming households. Average farm size was only 0.64 hectares in 2004 . It increased by more than a third by 2018, but still remained below a hectare.

Underlying the increase in average farm size is a significant increase in rentals of farm land. In Table 5 we also report the share of farming households that rent in land (second row), which can be thought of as the extensive margin of renting, and the share of land rented in among farming households, or the intensive margin. The share of rural households 
Table 4: Employment Share by Age Cohort

\begin{tabular}{|c|c|c|c|c|}
\hline Variable & 2004 & 2009 & 2014 & 2018 \\
\hline \multicolumn{5}{|c|}{ Panel A: Old } \\
\hline $\begin{array}{l}\text { Share of old in agriculture (\%) } \\
\text { of which: }\end{array}$ & 85.8 & 81.7 & 74.5 & 66.0 \\
\hline Farm operators (\%) & 38.5 & 35.2 & 30.3 & 25.3 \\
\hline rs $(\%)$ & 28.2 & 28.0 & 25.2 & 25.0 \\
\hline Part-time workers (\%) & 19.0 & 18.5 & 19.0 & 15.7 \\
\hline \multicolumn{5}{|c|}{ Panel B: Young } \\
\hline $\begin{array}{l}\text { Share of young in agriculture (\%) } \\
\text { of which: }\end{array}$ & 60.3 & 50.2 & 38.7 & 29.0 \\
\hline Farm operators (\%) & 19.1 & 13.8 & 9.3 & 6.7 \\
\hline Full-ti & 18.3 & 16.1 & 12.8 & 10.8 \\
\hline Part-time workers (\%) & 22.9 & 20.3 & 16.7 & 11.5 \\
\hline
\end{tabular}

Notes: All statistics are calculated from micro-level data from the RCRE survey, as shares out of the total numbers of old (Panel A) and young (Panel B) employed individuals in the survey. For each year the shares of farm operators, full-time and part-time workers sum up to the total share in agriculture for that cohort, save for rounding.

Table 5: Average Farm Size and Land Rentals

\begin{tabular}{lcccc}
\hline Variable & 2004 & 2009 & 2014 & 2018 \\
\hline Average farm size (ha) & 0.64 & 0.65 & 0.73 & 0.87 \\
Share of households renting-in land (\%) & 11.8 & 14.2 & 14.8 & 17.3 \\
Share of land rented-in (\%) & 10.7 & 17.2 & 20.8 & 30.0 \\
\hline
\end{tabular}

Notes: Average farm size is the total cultivated land over the total number of operating farms (households) from the RCRE survey data and expressed in hectares (ha). Statistics on land rentals are calculated among farming households in the Survey each year. Data are from authors' calculation from the micro data sample.

renting in land increased from 11.8 percent in 2004 to 17.3 in 2018, while the share of land rented in increased even more from 10.7 percent in 2004 to 30 percent by 2018. Although both increased, the expansion in land rental is primarily driven by the intensive margin and increases in the average amount of land rented in by households in the land rental market. The increase in land market activity is consistent with the alleviation of frictions in land markets through reforms that improved land security in China (see, for example, Chari et al., 2021). 
Table 6: Structural Transformation before 2004

\begin{tabular}{lcc}
\hline Variable & 1995 & 2002 \\
\hline Nationwide agricultural employment share (\%) & 48.0 & 42.2 \\
Share of households living in rural area (\%) & 75.4 & 72.6 \\
Share of labor days in agriculture among rural households (\%) & 63.6 & 58.2 \\
\hline Share of individuals in rural areas involved in agriculture (\%) & 73.6 & 67.5 \\
Share of full-time workers (\%) & 53.6 & 48.8 \\
Share of part-time workers (\%) & 19.9 & 18.8 \\
Average farm size (ha) & 0.57 & 0.59 \\
\hline
\end{tabular}

Notes: Nationwide statistics adjusted from the Chinese Statistics Yearbook. Employment statistics are calculated from micro-level data from the RCRE survey for 1995 and 2002, as shares out of the total numbers of employed individuals in the survey. Average farm size is the total amount of farm land over the total number of operating farms (households). The numbers are not directly comparable to those in the Survey over 2004-2018.

Earlier period 1995-2002. We draw on earlier waves of the RCRE survey to put structural change in the Chinese economy between 2004-2018 into perspective. Prior to 2004, there are signs of structural change however the process was much slower. Between 1995 and 2002, for example, the share of employment in agriculture at the national level fell from 48.0 percent to 42.2 percent, or one-half the annual rate that we observe after. This reflects only modest changes in the share of households living in rural areas, and the allocation of labor by these households to agriculture. Average farm size also remained more or less constant.

These features of China's structural transformation, which are prevalent in other lower income and emerging economies, motivate the framework we develop in the next section.

\section{A Model of Frictional Selection}

To study the role of insecure property rights and other labor mobility frictions on labor reallocation and aggregate outcomes, we develop a general equilibrium model of occupational and sectoral choices of heterogeneous individuals subject to idiosyncratic distortions. Our Roy-type model of occupational choice has four key novelties. First, within our model we embed families that make an endogenous decision of who within the family operates the 
family farm. Second, we introduce land institutions captured by: $(i)$ a household-level perceived cost of land insecurity; and $(\mathrm{ii})$ a barrier to the reallocation of land across families. Third, we introduce labor mobility barriers that are orthogonal to the land institutions, and capture all factors other than land that can impede labor mobility. And fourth, in contrast to the standard Roy model where occupational choices are binary, we allow for part-time employment.

\subsection{Description}

The population is organized into families living in villages, townships, and urban centres. At each date, two goods are produced: an agricultural good $(a)$ and a non-agricultural good $(n)$. Agricultural production is limited to villages, but production of the non-agricultural good can occur either in rural townships or urban centres, denoted by rural $(r)$ and urban (u), respectively. We assume the two non-agricultural sectors produce goods that are perfect substitutes. Village households can work locally in agriculture and the rural non-agricultural sector, or can migrate to the cities to work in the urban non-agricultural sector. Township (urban) households work only in the rural (urban) non-agricultural sector. We focus on the factors influencing the choice of occupations and locations of individuals and families living in villages.

Preferences and endowments. Households have preferences over the agricultural and non-agricultural goods represented by the non-homothetic utility function:

$$
u\left(c_{a}, c_{n}\right)=\phi \log \left(c_{a}-\bar{a}\right)+(1-\phi) \log \left(c_{n}\right), \quad \phi \in(0,1)
$$

where $c_{a}$ is consumption of the agricultural good, $\bar{a}$ is a minimum (subsistence) consumption requirement of the agricultural good, and $c_{n}$ is consumption of non-agricultural good. This specification allows us to capture income effects as a source of structural change.

There are three types of households: village families, township families, and urban fami- 
lies. Township and urban families are homogeneous and make no production decisions. Each is endowed with one unit of labor of average ability $\bar{h}$ and engaged in rural and urban nonagriculture production, respectively. There is an exogenous mass $N_{r}$ of township families and $N_{u}$ of urban families.

Village families are at the core of all decisions involving agricultural production, occupational choices, and migration. Village families can be engaged either in agriculture or non-agriculture. There is a unit measure of village families indexed by $i$ comprising $J$ individuals, indexed with $j=1,2, \ldots J$. Each individual family member is endowed with a pair of abilities $\left(s_{i j}, h_{i j}\right)$, where $s_{i j}$ is ability as a farm operator and $h_{i j}$ is the earning ability in nonagriculture. Families are subject to land insecurity costs and individual family members are subject to idiosyncratic labor mobility frictions. Individual-level abilities and idiosyncratic frictions are drawn from a joint multivariate distribution with $c d f \Phi$.

Individual family members can be either young or old. Young and old individuals differ only in terms of the multivariate distribution $\Phi$, from which their abilities and idiosyncratic frictions are drawn. Given that young and old individuals face the same choices, we abstract from cohort differences below to simplify the exposition of the model.

Individuals are endowed with one unit of time in each period that is supplied inelastically, and can work as a full-time farm operator or as an agricultural or non-agricultural worker on a full-time or part-time basis. The total number of individuals in villages is $J$, and the total amount of land is $L$.

Technologies. The non-agricultural good is produced using the constant returns to scale technology,

$$
Y_{k}=A_{k} H_{k}, \quad k \in\{r, u\},
$$

where $A_{k}$ is the productivity parameter of the rural $(r)$ and urban $(u)$ non-agricultural sectors and $H_{k}$ is the total labor input in efficiency units in the corresponding sector.

The agricultural good is produced by farms. A farm is a decreasing-returns technology 
that requires the inputs of a farm operator with managerial ability $s_{i j}$, cultivated land $l_{i j}$, and farm labor $n_{i j}$ :

$$
y_{i j}=A s_{i j}\left(l_{i j}^{\theta} n_{i j}^{1-\theta}\right)^{\gamma}
$$

where $y_{i j}$ is agricultural output, $A$ is an agricultural technology parameter, $\theta \in(0,1)$ captures the importance of land relative to labor in production, and $0<\gamma<1$ captures returns to scale at the farm-level.

Markets. A large number of firms operate each of the rural and urban non-agricultural technologies in competitive markets. We set the non-agricultural good as the numeraire and normalize its price to one. We denote by $w_{r}$ the competitive price of efficiency units of labor in the rural non-agricultural sector and $w_{u}$ the price in the urban non-agricultural sector. Profit maximization implies that wages equate the marginal product of efficiency units of labor in each sector,

$$
w_{u}=A_{u}, \quad w_{r}=A_{r}
$$

Farms also operate in competitive markets of land, labor, and output. We denote by $p$ the relative price of the agricultural good.

\subsection{Idiosyncratic Distortions}

Families and individuals are subject to idiosyncratic land and labor mobility distortions.

Land market institutions. We capture two dimensions of land market institutions in China at the family-level. First, operating a family farm is subject to a barrier to the reallocation of land across individuals. As in Adamopoulos et al. (2021), we model this barrier as an implicit distortion on output $\tau_{i j}$ imposed on individual $j$ in family $i$. This implicit distortion captures the administrative allocation of land across households in villages, and has the property that more productive individuals cannot necessarily access more land as in an unfettered land market. Quantitatively, the size of the implicit distortion captures the 
extent to which the amount of land farmed by an individual differs from farm size without the impediment. These implicit distortions introduce misallocation within the agricultural sector.

Second, if a household does not farm the land they have been administratively allocated, and all its members work in non-agriculture, the land may be reallocated by the village to other households. In the case of land expropriation by the state, the household may not be compensated. We capture the perceived land insecurity by household $i$ as an income loss, modeled as an idiosyncratic fixed cost $b_{i}$ faced by the family. This modeling choice allows a common land institution to differentially affect individual households based on each household's perceptions of its effect. As such, it summarizes the de-facto rather than the dejure land institution. These perceived costs may deter families from completely abandoning their land in the village, inducing them to assign a family member to operate the land even with low productivity.

Labor mobility frictions. Individual labor supply choices outside agriculture are subject to idiosyncratic distortions, modeled as barriers on wage income. An individual $j$ in family $i$ faces a wage-barrier $\xi_{i j}^{r}$ if they work in rural non-agriculture locally, and a wage-barrier $\xi_{i j}^{u}$ if they work in urban non-agriculture. In other words, we allow for the possibility that the barriers to reallocating labor supply from agriculture to the rural and urban non-agriculture sectors may differ (Brandt and Zhu, 2010). These barriers are catchalls for all the factors that may impede the reallocation of labor to the non-agricultural sectors, exclusive of the land institutions.

\subsection{Village Families}

We describe the occupational choices of village families in two steps. First, we characterize the income of each individual $j$ in family $i$ from working in each possible occupation: agricultural worker, rural non-agricultural worker, urban non-agricultural worker, and farm 
operator. Second, we characterize family $i$ 's endogenous allocation of individual members to occupations to maximize total family income.

Full-time non-agricultural worker. An individual $j$ in family $i$ working full-time in nonagricultural sector $k \in\{r, u\}$, facing labor mobility barrier $\xi_{i j}^{k}$, earns net income $w_{k} h_{i j}\left(1-\xi_{i j}^{k}\right)$. The individual works in the urban non-agricultural sector if $w_{u}\left(1-\xi_{i j}^{u}\right)>w_{r}\left(1-\xi_{i j}^{r}\right)$. We denote the wage and barrier in non-agriculture as those associated with the highest net earnings sector,

$$
w_{i j}^{n}=\mathbb{1}\left[w_{u}\left(1-\xi_{i j}^{u}\right)>w_{r}\left(1-\xi_{i j}^{r}\right)\right] w_{u}+\mathbb{1}\left[w_{u}\left(1-\xi_{i j}^{u}\right) \leqslant w_{r}\left(1-\xi_{i j}^{r}\right)\right] w_{r}
$$

and

$$
\xi_{i j}=\mathbb{1}\left[w_{u}\left(1-\xi_{i j}^{u}\right)>w_{r}\left(1-\xi_{i j}^{r}\right)\right] \xi_{i j}^{u}+\mathbb{1}\left[w_{u}\left(1-\xi_{i j}^{u}\right) \leqslant w_{r}\left(1-\xi_{i j}^{r}\right)\right] \xi_{i j}^{r} .
$$

where $\mathbb{1}[$.$] takes the value of 1$ if the statement in the brackets is true and 0 otherwise. We then express the income from full-time non-agricultural work as

$$
i_{i j}^{F N}=w_{n}\left(1-\xi_{i j}\right) h_{i j}
$$

where the superscript $F N$ denotes "full-time non-agriculture".

Full-time agricultural worker. If an individual $j$, from family $i$, works as a full-time agricultural worker they earn wage income. The skills of agricultural workers are homogeneous across all individuals, and normalized to 1 . This implies that only an individual's agricultural ability $s_{i j}$ is relevant to operating the farm. We denote the agricultural wage rate as $w$, which can differ from the wage rates in the non-agricultural sectors. We assume that family labor and hired labor are perfect substitutes; hence, in our notation all agricultural labor is paid at rate $w$. We denote the income from full-time agricultural work as $i_{i j}^{F A}=w$, where the superscript $F A$ denotes "full-time agriculture." 
Part-time worker. Given that in the data workers often earn wages in both agriculture and non-agriculture, we allow individuals to work part-time. We denote by $n_{i j}$ the labor supply of individual $j$ from family $i$ to agriculture. The labor supply of the same individual to non-agriculture is $\left(1-c-n_{i j}\right)$, where $c$ denotes a fixed cost in terms of time associated with working part-time. ${ }^{5}$ An individual that works part time in both agriculture and nonagriculture obtains income $h_{i j} \cdot w_{n} \cdot\left(1-\xi_{i j}\right) \cdot\left(1-c-n_{i j}\right)$ from non-agriculture and $w \cdot$ $\kappa \cdot n_{i j}^{\nu}$ from agriculture, where $\kappa$ measures the relative efficiency of labor input in the two sectors. The exponent parameter $\nu<1$ captures decreasing returns of labor supply to the agricultural sector. The concavity allows for incomplete specialization across sectors for part-time workers.

The income of a part-time worker is

$$
h_{i j}\left(1-c-n_{i j}\right) w_{i j}^{n}\left(1-\xi_{i j}\right)+w \kappa n_{i j}^{\nu}
$$

Taking the first-order condition of income with respect to labor supply in agriculture $n_{i j}$, we obtain the optimal agricultural labor supply,

$$
n_{i j}^{*}=\min \left\{\left(\frac{\nu \kappa w}{h_{i j} w_{i j}^{n}\left(1-\xi_{i j}\right)}\right)^{\frac{1}{1-\nu}}, 1-c\right\}
$$

The corresponding income is then given by

$$
i_{i j}^{P T}=h_{i j}\left(1-c-n_{i j}^{*}\right) w_{i j}^{n}\left(1-\xi_{i j}\right)+w \kappa\left(n_{i j}^{*}\right)^{\nu}
$$

where the superscript $P T$ denotes "part-time worker."

Using the above notation and characterization, we can express effective labor supply to

\footnotetext{
${ }^{5}$ We allow for different fixed costs for the rural $\left(c_{r}\right)$ and urban $\left(c_{u}\right)$ non-agricultural sectors.
} 
the agricultural sector as,

$$
n_{i j}=\left\{\begin{array}{l}
1, \text { if } i_{i j}^{F A} \geqslant i_{i j}^{F N} \text { and } i_{i j}^{F A} \geqslant i_{i j}^{P T} \\
0, \text { if } i_{i j}^{F N} \geqslant i_{i j}^{F A} \text { and } i_{i j}^{F N} \geqslant i_{i j}^{P T}, \\
\kappa\left(n_{i j}^{*}\right)^{\nu}, \text { if } i_{i j}^{P T} \geqslant i_{i j}^{F A} \text { and } i_{i j}^{P T} \geqslant i_{i j}^{F N} .
\end{array}\right.
$$

Within family allocation in villages. To operate a farm in agriculture, each family $i$ must assign one individual to be a full-time farm operator in order to produce the agricultural good and retain their allocated land. Productivity of the family farm is determined by the ability of the operator. If individual $j$ operates family $i$ 's land, farming profits are given by $\pi\left(s_{i j}, \tau_{i j}\right)$, where $\tau_{i j}$ is the individual-specific output distortion that constitutes a barrier to input reallocation across farms. The profit maximization problem that individual $j$ of family $i$ faces is given by

$$
\pi\left(s_{i j}, \tau_{i j}\right)=\tau_{i j} p A s_{i j}\left(l_{i j}^{\theta} n_{i j}^{1-\theta}\right)^{\gamma}-q l_{i j}-w n_{i j},
$$

where $l_{i j}$ and $n_{i j}$ are the land and labor input demands. It is straightforward to show that the optimal input demands and output supply are given by,

$$
\begin{gathered}
l_{i j}=\left(s_{i j} \tau_{i j}\right)^{\frac{1}{1-\gamma}}(\gamma p A)^{\frac{1}{1-\gamma}}\left(\frac{\theta}{q}\right)^{\frac{1-(1-\theta) \gamma}{1-\gamma}}\left(\frac{1-\theta}{w}\right)^{\frac{(1-\theta) \gamma}{1-\gamma}} \\
n_{i j}^{d}=\left(s_{i j} \tau_{i j}\right)^{\frac{1}{1-\gamma}}(\gamma p A)^{\frac{1}{1-\gamma}}\left(\frac{\theta}{q}\right)^{\frac{\theta \gamma}{1-\gamma}}\left(\frac{1-\theta}{w}\right)^{\frac{1-\theta \gamma}{1-\gamma}} \\
y_{i j}=s_{i j}^{\frac{1}{1-\gamma}} \tau_{i j}^{\frac{\gamma}{1-\gamma}} A(\gamma p A)^{\frac{\gamma}{1-\gamma}}\left(\frac{\theta}{q}\right)^{\frac{\theta \gamma}{1-\gamma}}\left(\frac{1-\theta}{w}\right)^{\frac{(1-\theta) \gamma}{1-\gamma}}
\end{gathered}
$$

and optimal farm profits by

$$
\pi_{i j}=(1-\gamma) p y_{i j} \tau_{i j} \propto\left(s_{i j} \tau_{i j}\right)^{\frac{1}{1-\gamma}}
$$

We now characterize how the household allocates its members across occupations. If 
individual $j$ is chosen to be the farm operator, total income is given by

$$
I_{i}^{a}(\text { operator }=j)=\pi_{i j}+\sum_{k \neq j} i_{i k}=s_{i j} \Omega_{i j}+\sum_{k \neq j} \max \left\{i_{i k}^{F N}, i_{i k}^{F A}, i_{i k}^{P T}\right\}
$$

where $\Omega_{i j}$ depends on a collection of constants and individual-specific farm distortion $\tau_{i j}$. Operating in agriculture, the household chooses the farm operator that maximizes total income,

$$
I_{i}^{a}=\max _{j \in J}\left\{I_{i}(\text { operator }=j)\right\}
$$

If the household chooses not to participate in agricultural production, then no family member is assigned to be a farm operator. However, the household's allocated land may be reallocated or expropriated without compensation. The loss associated with the land insecurity is $b_{i}$, which differs across households. In this case, total income is given by

$$
I_{i}^{n}=\sum_{j} \max \left\{i_{i j}^{F N}, i_{i j}^{F A}, i_{i j}^{P T}\right\}-b_{i}
$$

The household chooses to operate a farm if and only if $I_{i}^{a} \geqslant I_{i}^{n}$. Hence, total income of village family $i$ is

$$
I_{i}=\max \left\{I_{i}^{a}, I_{i}^{n}\right\}
$$

We define an indicator variable $D_{i}$ for family $i$, with $D_{i}=1$ if family $i$ operates a farm in agriculture and $D_{i}=0$ otherwise. An individual will be one of the following six occupational types: farm operator, full-time agricultural worker, full-time rural or urban non-agricultural worker, part-time agricultural and non-agricultural worker (urban or rural). For individual members, we use the following notation to represent optimal occupation choices. We define indicator variables, with $D_{i j}^{O}=1$ if individual $j$ is the farm operator and $D_{i j}^{O}=0$ otherwise. We denote by $D_{i j}^{F A}=1$ if individual $j$ is a full-time agricultural worker, $D_{i j}^{F N}=1$ if a full-time non-agricultural worker (rural or urban), and $D_{i j}^{P T}=1$ if a part-time agricultural and non-agricultural worker (rural or urban). We define an indicator variable $R_{i j}$, where 
$R_{i j}=1$ if individual $j$ earns a higher net wage (adjusted for labor mobility frictions) in the rural than in the urban non-agricultural sector.

\subsection{Equilibrium}

A competitive equilibrium is a set of prices $\left\{w, w_{r}, w_{u}, p, q\right\}$, allocations of the farm operator $l_{i j}, n_{i j}^{d}, \pi_{i j}, y_{i j}$; village family income $I_{i}$, occupation allocations $D_{i}, D_{i j}^{O}, D_{i j}^{F A}, D_{i j}^{F N}, D_{i j}^{P T}$, $R_{i j}$, and consumption $\left(c_{a i}, c_{n i}\right)$, and consumption for the township and urban households $\left(c_{a}^{r}, c_{n}^{r}\right)$ and $\left(c_{a}^{u}, c_{n}^{u}\right)$, such that: $(i)$ Given prices, farm operators maximize profits $\pi_{i j}$ and $l_{i j}$, $n_{i j}^{d}$ are optimal factor demands. (ii) Given prices, non-agricultural firms maximize profits, which imply $w_{u}=A_{u}$ and $w_{r}=A_{r}$. (iii) Given prices, village families maximize income $I_{i}$ by choosing labor supply $n_{i j}$ from equation (5) and occupations $D_{i}, D_{i j}^{O}, D_{i j}^{F A}, D_{i j}^{F N}, D_{i j}^{P T}$, $R_{i j}$ to solve problems (7), (8), and (9). (iv) Given prices and income $I_{i}$, village households choose consumption $\left(c_{a i}, c_{n i}\right)$ to maximize utility in equation (1). Similarly, given prices, township and urban households choose consumption $\left(c_{a}^{r}, c_{n}^{r}\right)$ and $\left(c_{a}^{u}, c_{n}^{u}\right)$ to maximize utility subject to income $w_{r} \bar{h}$ and $w_{u} \bar{h}$. (v) Markets clear:

- Land

$$
\int_{i} D_{i} \sum_{j \in i} l_{i j} D_{i j}^{O} d i=L
$$

- Agricultural labor

$$
\int_{i} \sum_{j \in i}\left(1-D_{i} D_{i j}^{O}\right) n_{i j} d i=\int_{i} D_{i} \sum_{j \in i} n_{i j}^{d} D_{i j}^{O} d i
$$

- Non-agricultural labor

$$
\begin{aligned}
& H_{r}^{s}=\int_{i} \sum_{j \in i}\left(1-D_{i} D_{i j}^{O}\right) R_{i j}\left[\left(1-n_{i j}-c_{r}\right) D_{i j}^{P T}+D_{i j}^{F N}\right] h_{i j} d i+\bar{h} N_{r}, \\
& H_{u}^{s}=\int_{i} \sum_{j \in i}\left(1-D_{i} D_{i j}^{O}\right)\left(1-R_{i j}\right)\left[\left(1-n_{i j}-c_{u}\right) D_{i j}^{P T}+D_{i j}^{F N}\right] h_{i j} d i+\bar{h} N_{u},
\end{aligned}
$$


where $\bar{h}$ is the average ability of township and urban families of size $N_{r}$ and $N_{u}$.

- Agricultural and non-agricultural goods:

$$
\begin{gathered}
\int_{i} c_{a i} d i+N_{r} c_{a}^{r}+N_{u} c_{a}^{u}=\int_{i} \sum_{j \in i} D_{i} D_{i j}^{O} y_{i j} d i \\
\int_{i} c_{n i} d i+N_{r} c_{n}^{r}+N_{u} c_{n}^{u}=A_{r} H_{r}+A_{u} H_{u} .
\end{gathered}
$$

\section{Estimation}

To estimate our model we use two main data sources: $(i)$ household- and individual-level survey data from the Research Center for the Rural Economy (RCRE) for the period 20042018; and (ii) aggregate data from the Chinese Statistics Yearbook supplemented with revised sectoral employment series from Brandt and Zhu (2010) and Yao and Zhu (2020). A more detailed description of the data is provided in Appendix A.

Our estimation strategy involves two steps. First, we parameterize the distributions for sectoral abilities, land market institutions, and labor mobility frictions of village families. Second, we estimate the parameters of the model to match model moments with empirical moments from the survey and aggregate data.

\subsection{Parameterization}

In our model description we suppressed the notation by age, however in our quantitative implementations we explicitly distinguish between young and old household members. Individuals are classified as old if they are 45 years of age or older. ${ }^{6}$ This allows us to examine the effect of age differences for family, occupational, and sectoral selection and the aggregate implications for productivity and structural change. The young and old individuals

\footnotetext{
${ }^{6}$ Our results are robust to reasonable variations in the old-age threshold.
} 
differ only in terms of the distributions from which they draw their individual-level sectoral abilities and their labor mobility frictions.

Ability distribution and family structure. Each individual $j$, in family $i$, draws an farm-operator ability $s_{i j}$ and a non-agricultural ability $h_{i j}$. We allow for individual abilities to be correlated across members of the same family. In addition, we allow for abilities to be correlated across sectors. In particular, the non-agricultural ability of individual $j$ in family $i$ is given by,

$$
\log \left(h_{i j}\right)=\log \left(h_{i}^{H}\right)+\log \left(h_{i j}^{I}\right)
$$

where $h_{i}^{H}$ is a common component for all individuals within family $i$ and $h_{i j}^{I}$ is individual $j$ 's idiosyncratic component. Without taking a stance on the source, the common component can capture, for example, the correlation of innate ability or accumulable skills across family members. The agricultural ability of individual $j$, in family $i$, is given by,

$$
\log \left(s_{i j}\right)=\log \left(s_{i}^{H}\right)+\log \left(s_{i j}^{I}\right)+\lambda \log \left(h_{i j}\right)
$$

where $s_{i}^{H}$ is the common family component, $s_{i j}^{I}$ the individual component, and $\lambda \log \left(h_{i j}\right)$ is the component that is correlated with non-agricultural ability. Note that $\lambda$ governs the correlation between agricultural and non-agricultural abilities of the same individual. Finally, we denote the probability of an individual being old by $p_{o}$.

We assume that all the ability components follow log-normal distributions. The family components of farming ability $s_{i}^{H}$ and non-agricultural ability $h_{i}^{H}$ are drawn from log-normal distributions with mean zero and standard deviations $\sigma_{s}^{H}$ and $\sigma_{h}^{H}$. The levels of the individual components of agricultural and non-agricultural ability are allowed to differ between young and old individuals. We normalize the mean of individual ability, $s_{i j}^{I}$ and $h_{i j}^{I}$, to zero for the old and denote by $\mu_{y}^{s}$ and $\mu_{y}^{h}$ the mean of the individual component of ability for the young. The standard deviations of $s_{i j}^{I}$ and $h_{i j}^{I}$ are the same within each cohort denoted by $\sigma_{s}^{I}$ and 
$\sigma_{h}^{I}$

Idiosyncratic farm distortions. Individual $j$ in family $i$ faces implicit distortions to operating a farm, measured by $\tau_{i j}$, which captures one component of the land market institutions in China. We allow for the farm distortion to consist of a component that is correlated with farm-operating ability and an uncorrelated component, ${ }^{7}$

$$
\log \left(\tau_{i j}\right)=\underbrace{\zeta \log \left(s_{i j}\right)}_{\text {correlated distortions }}+\underbrace{\varepsilon_{i j}}_{\text {uncorrelated }}
$$

where $\zeta$ captures the correlation with farming ability $s_{i j}$, and the noise component $\varepsilon_{i j}$ is drawn from a normal distribution with mean zero and standard deviation $\sigma_{\varepsilon}$.

Idiosyncratic labor mobility frictions. We assume that labor mobility barriers faced by the young in the rural and urban non-agricultural sectors are given by

$$
\xi_{i j}^{k}=\frac{\exp \left(\mu_{k}+\varepsilon_{i j}^{k}\right)}{1+\exp \left(\mu_{k}+\varepsilon_{i j}^{k}\right)}, \quad k \in\{r, u\} .
$$

This parametric form guarantees that labor mobility barriers are bounded between zero and one, where $\mu_{k}$ governs the level of barriers and $\varepsilon_{i j}^{k}$ their idiosyncratic component, which we assume follows a normal distribution with mean zero and standard deviation $\sigma_{\xi}$. Labor mobility barriers of the old have the same parametric form, except that the level is shifted by $\mu_{k}^{o}$, thereby allowing for labor mobility barriers to differ between age cohorts.

Family land insecurity cost. In our model, $b_{i}$ summarizes the perceived income drop that family $i$ suffers from potentially losing access to rural land if not farming. We assume

\footnotetext{
${ }^{7}$ This is similar to how idiosyncratic wedges are modeled in Bento and Restuccia (2017) and Restuccia (2019).
} 
that $b_{i}$ differs across families as follows,

$$
\log \left(b_{i}\right)=\mu_{b}+\varepsilon_{i}^{b}
$$

where $\varepsilon_{i}^{b}$ follows a normal distribution with mean zero and standard deviation $\sigma_{b}$.

\subsection{Identification}

Overall, there are 32 parameters to be determined in our model, including the parameters of the ability distributions and distortions discussed above. In Appendix B we provide a detailed explanation of how the parameters are assigned values or estimated. In this section, we provide a brief overview of our approach, focusing on the elements that are non-standard.

Out of the 32 parameters, 10 are either normalized or set based on a priori information. The remaining parameters are estimated jointly in order that our model-generated moments for key variables match the corresponding empirical moments. While the parameters are jointly determined, certain moments are more relevant for identifying key parameters. The distribution of employment across sectors, occupations, and locations helps us identify the fixed costs to part-time work in rural and urban non-agriculture $\left(c^{r}\right.$ and $\left.c^{u}\right)$, the relative sectoral efficiency parameters $\left(A_{u}, \kappa, \bar{h}\right)$ and the subsistence constraint $\bar{a}$.

Ability distributions. The moments of the ability distributions are chosen to match empirical moments of dispersion in sectoral incomes (non-agriculture) and farm TFP (agriculture). In particular, the dispersion of the family and individual components of nonagricultural ability are identified through the standard deviation of (full-time) non-agricultural wage income and the rank correlation of non-agricultural wage incomes within the family. The dispersion of farm-operating ability is chosen to match the dispersion of farm TFP in the production data, with the parameter capturing the correlation to non-agricultural ability $(\lambda)$ identified from the correlation of non-agricultural wage income with farm profit within the family. 
Land market distortions. The land institutions in our model are summarized by the individual-level farm distortion $\tau_{i j}$, and the family-level perceived income loss associated with land insecurity if the land is not operated by a family member. To identify the parameters of the $\tau_{i j}$ distribution we first estimate a summary measure of farm-specific distortions, inferred as a weighted average of actual input deviations from their efficient levels (given farm productivity), what the literature calls TFPR (Hsieh and Klenow, 2009). Then, following Adamopoulos et al. (2021), the correlation of farm distortions with farmer productivity and the dispersion of their non-systematic component are chosen to match the dispersion of TFPR and the correlation of farm TFP and TFPR.

The component of land market distortions that relates to land insecurity $b_{i}$ is novel in our analysis, and the indirect inference of its level and dispersion across families requires more explanation. We identify $\mu_{b}$ to match the share of village families that operate farms in 2004 (about 72 percent). If there was a homogeneous fixed cost $b_{i}$ for all families then those with the highest non-agricultural ability would move out of agriculture, and the lowest nonagricultural ability families would remain in farming. This would result in a counter-factually large non-agricultural wage gap between farming and non-farming families. Introducing dispersion across families in the fixed cost $b_{i}$ ensures that some low non-agricultural ability families exit farming while some high non-agricultural ability families choose to remain in farming. This results in a more compressed wage gap between non-farming and farming households. In our baseline calibration, we choose the dispersion of $b_{i}$ to match exactly the wage gap between farming and non-farming households.

Labor mobility frictions. Conditional on relative productivities (determined by relative employment shares as discussed), the means of the labor mobility frictions to rural and urban non-agriculture $\left(\mu_{r}, \mu_{u}\right)$ are chosen to match two income differentials: $(i)$ the difference between rural non-agricultural income and farm profits; and (ii) rural versus urban nonagricultural wage income. If there was no dispersion in the labor mobility barriers, all 
individuals would face the same migration cost equal to the mean. This would imply that in equilibrium old individuals would prefer to move to the rural non-agricultural sector, while all young individuals would prefer to move to the urban non-agricultural sector. However, in the data we do not observe this exact sorting: There are old individuals in urban nonagriculture and young individuals in rural non-agriculture. Allowing for dispersion in labor mobility barriers can accommodate these non-hierarchical patterns. We select $\sigma_{\xi}$ to exactly match the share of old cohorts in urban non-agriculture.

Other cohort differences. The difference in farming profit between young and old operators helps determine the young-old agricultural productivity ratio $\mu_{s}^{y}$. We use moments on employment shares by age cohort and the young versus old non-agricultural wage differential

to separately identify three parameters: the young-old non-agricultural ability difference $\mu_{h}^{y}$ and the young-old labor mobility barriers differences $\mu_{o}^{r}$ and $\mu_{o}^{u}$.

We note that model parameters do not always uniquely determine model implied moments. Our identification derives from the sensitivity of the model moments to specific parameters as well the direction of the effect. Appendix B outlines in more detail how model parameters map to model moments. The estimated parameter values are reported in Table B.3 in Appendix B. The empirical moments of key variables, along with the implied model moments are reported in Table 7 . Overall, the estimated model matches the data targets very well.

\subsection{Discussion}

The calibrated values of some parameters require further discussion. For younger cohorts, the estimated labor mobility barriers are higher in the rural non-agricultural sector than in the urban non-agricultural sector. This could be because the urban non-agricultural sector provides non-pecuniary benefits for young cohorts, such as life-cycle growth, urban amenities, or social welfare, which effectively reduce the labor mobility barrier. It may also 
Table 7: Targeted Moments, Data and Model

\begin{tabular}{lrr}
\hline Moments & Data & Model \\
\hline Employment share among village individuals: & & \\
$\quad$ Part-time: & 0.160 & 0.157 \\
$\quad$ Rural non-agriculture & 0.053 & 0.059 \\
$\quad$ Urban non-agriculture & 0.146 & 0.142 \\
$\quad$ Full-time: & 0.148 & 0.147 \\
$\quad$ Rural non-agriculture & 0.278 & 0.278 \\
$\quad$ Urban non-agriculture & 0.719 & 0.718 \\
Median fraction of part-time hours in agriculture & & \\
Share of village households with farm operators & -0.156 & -0.156 \\
Sectoral wage differentials: & 0.182 & 0.182 \\
$\quad$ Urban nonagr. versus rural nonagr. & & \\
$\quad$ Rural nonagr. versus farming & -0.282 & -0.283 \\
Family wage differentials: & & \\
$\quad$ Average nonagr wage, with/without operators & -0.161 & -0.162 \\
Young-old differentials: & -0.056 & -0.055 \\
$\quad$ Urban non-agriculture & 0.054 & 0.054 \\
$\quad$ Rural non-agriculture & & \\
$\quad$ Farm operators & 0.369 & 0.365 \\
Age distribution: & 0.548 & 0.544 \\
$\quad$ Some rural non-agriculture & & \\
$\quad$ Full-time agriculture including farm operators & 0.662 & 0.664 \\
Wage dispersion among full-time non-agr. workers: & 0.635 & 0.634 \\
$\quad$ Standard deviation & 0.556 & 0.967 \\
$\quad$ Within-family correlation & 0.555 \\
Correlation of non-agricultural wage income and farm profit & 0.082 & 0.082 \\
Agricultural production: & & 2.575 \\
$\quad$ Standard deviation of farm TFP & & \\
$\quad$ Standard deviation of farm TFPR & & \\
$\quad$ Correlation of farm TFP and TFPR & & \\
Nominal agr. to non-agr. labor productivity ratio & & \\
\hline & & 0.576 \\
\hline
\end{tabular}

Notes: Targeted data moments and estimated model. 
reflect regional heterogeneity. As we document below, our finding that rural labor-mobility barriers are higher is driven by behavior in remote rural areas rather than peri-urban areas. This suggests that it could be due to labor market imperfections in remote rural areas. We discuss this issue in more detail in Appendix C.

We also find that the old face substantially higher labor mobility barriers than the young, especially in the urban non-agricultural sector. This results from the fact that the old are disproportionately under-represented in the urban non-agricultural sector and over-represented in agriculture, consistent with findings in Hobijn et al. (2018). The labor mobility barrier in our framework is a residual impediment to migration that is not captured by land insecurity such as the institutional costs tied to "Hukou" restrictions in China, a preference for working locally, and re-training costs associated with switching sectors (Hobijn et al., 2018).

We also estimate a large negative value for $\zeta$, consistent with the misallocation literature emphasizing the role of land institutions in generating distortions that are highly correlated with farm TFP. In particular, our estimate of $\zeta$ is consistent with measured distortions in Adamopoulos et al. (2021) associated with the land institution in China for the period prior to the early 2000s.

\section{Quantitative Analysis}

We evaluate the quantitative role of land security and labor mobility frictions in 2004, the year of our baseline estimation, and then analyze their evolution over time. We also study the link between land insecurity and misallocation in agriculture.

\subsection{Land Security and Labor Mobility Barriers}

To disentangle the importance of land insecurity $\left(b_{i}\right)$ relative to labor mobility barriers $\left(\xi_{i j}^{r}\right.$ and $\left.\xi_{i j}^{u}\right)$ on outcomes, we perform two quantitative experiments from the benchmark economy. First, we assess the role of land security by setting $b_{i}=0$ for all families. Second, 
we eliminate labor mobility barriers by setting $\xi_{i j}^{r}$ and $\xi_{i j}^{u}$ to zero for all individuals and families. We examine the quantitative implications of these changes for sector employment, agricultural labor productivity, and other aggregate outcomes.

Table 8: The Role of Land Security and Labor Mobility Barriers

\begin{tabular}{lcrr}
\hline & Baseline & $\begin{array}{r}\text { Land } \\
\text { Security }\end{array}$ & $\begin{array}{r}\text { No Labor } \\
\text { Barriers }\end{array}$ \\
\hline Village families operating farms (\%) & & 41.8 & 50.2 \\
Agricultural employment share among villagers (\%) & 56.6 & 51.1 & 47.3 \\
$\Delta$ Agricultural output (\%) & - & -0.3 & -6.6 \\
$\Delta$ Agricultural labor productivity (\%) & - & +10.5 & +11.8 \\
$\Delta$ Median log farm operator ability (\%) & - & +10.6 & +3.3 \\
$\Delta$ Non-agricultural output (\%) & - & +2.3 & +8.7 \\
$\Delta$ Real GDP per capita (\%) & & +1.9 & +5.2 \\
Within-household selection in farming: & 56.0 & 60.3 & 57.6 \\
$\quad$ \% of farm operators with highest $s_{i j}$ &
\end{tabular}

Notes: Statistics for the baseline model, counterfactual no land frictions $\left(b_{i}=0\right.$ for all $\left.i\right)$, and counterfactual no labor mobility barriers $\left(\xi_{i j}^{r}=\xi_{i j}^{u}=0\right)$. The percentage of village households operating farms and sectoral employment shares among villagers are in levels, while all other statistics are displayed as differences compared to the baseline model.

The results of these counterfactual experiments are presented in Table 8. Eliminating the cost of land insecurity $\left(b_{i}=0\right)$ in the second column results in a sharp drop in the fraction of households who operate farms from 71.8 percent to only 42.7 percent. This suggests that 30 percent of farms in the baseline are "zombie" farms, i.e., low productivity rural households that operate farms simply to avoid losing their allocated land. As a result, average farm size rises by 68 percent with the exit of "zombie" farms. The share of employment in agriculture among village households falls much less, from 56.6 percent to 51.1 percent. This reflects the fact that the improvement in land security increases the average ability of farm operators by improving selection into agriculture within as well as between households, which also increases the demand for farm labor. The ability of the median operator rises by 10.6 percent as the percentage of farming households for which the farm operator has the highest agricultural ability increases from 56 percent in the baseline to 60.3 percent. Overall, agricultural labor productivity rises by 10.5 percent. With labor released from 
agriculture to non-agriculture, aggregate non-agricultural output increases by 2.3 percent. The total increase in real GDP per capita, calculated using the chain-type quantity index, is 1.9 percent.

Eliminating labor mobility barriers $\left(\xi_{i j}^{r}=\xi_{i j}^{u}=0\right)$ in the third column of Table 8 has similar effects on key moments in the data, however several differences emerge. First, removal of these constraints results in a smaller reduction in the share of households operating farms, but a larger reduction in employment. Accompanying these changes are smaller improvements in farm operator ability through selection, which only rises $3.3 \%$. Second, there are much larger reductions in output in farming that is more than offset by even larger gains in non-agricultural output. As a result, real GDP per capita rises by 5.2 percent compared to 1.9 percent when we eliminate tenure insecuriy.

We also use our framework to shed light on the fact that the old are much more likely to be involved in farming. Two forces are at work. First, older cohorts have a comparative advantage in agriculture (recall that the young cohorts have higher average ability in both dimensions but especially in non-agriculture). And second, labor mobility barriers are more severe for the old than for the young. Both factors predispose families to choose older family members as the farm operator.

Table 9 reports separately agricultural employment shares for young and old villagers and the proportion that are operators versus workers. For the baseline model, 66.5 percent of old individuals work in agriculture only, either as farm operators or full-time agricultural workers, compared to 38.0 percent of young individuals. Eliminating land frictions, agricultural employment shares decline among both young and old cohorts, with a slightly larger decline among the old. Eliminating labor mobility barriers, the agricultural employment shares also decline substantially among both young and old cohorts, but especially among the old cohorts. This behavior is consistent with our finding that labor mobility barriers are much more severe for old cohorts, and more important in explaining the young-old gap in agricultural employment. After eliminating both frictions, a gap in agricultural employment 
between young and old of 10.7 percentage points still exists. Out of a total gap of 28.5 percentage points in the baseline, 16.8 percentage points are the product of labor mobility barriers and 2.1 percentage points due to land insecurity, hence land insecurity accounts for only about $10 \%$ of age gap in agricultural employment, but note however that land insecurity contributes about $40 \%$ to age gap among farm operators.

Table 9: Occupation Differences between Cohorts

\begin{tabular}{lrrrr}
\hline & Baseline & $\begin{array}{r}\text { Land } \\
\text { Security }\end{array}$ & $\begin{array}{r}\text { No Labor } \\
\text { Barriers }\end{array}$ & Both \\
& & & & \\
\hline Old & & & & \\
$\quad$ Agricultural employment share (\%) & 66.5 & 58.6 & 44.3 & 40.3 \\
$\quad$ Operator & 31.8 & 18.8 & 19.1 & 14.2 \\
$\quad$ Worker & 34.7 & 39.8 & 25.2 & 26.1 \\
$\quad$ Young & & & & \\
$\quad$ Agricultural employment share (\%) & 38.0 & 32.2 & 32.6 & 29.6 \\
$\quad$ Operator & 18.5 & 11.1 & 15.1 & 11.6 \\
$\quad$ Worker & 19.5 & 21.1 & 17.4 & 18.0 \\
\hline
\end{tabular}

Notes: Share of old and young cohorts among village households in agricultural employment (and between operator and agricultural worker) for the baseline model and counterfactuals.

\subsection{Evolution of Frictions Over Time}

We leverage our sample data through 2018 to assess the evolution of land insecurity and labor mobility frictions over time. Our baseline model is calibrated to 2004 moments. We re-calibrate the model to match data moments in 2018 and then perform the following counterfactual experiments. ${ }^{8}$ First, we change land frictions in 2004 to match their median level in 2018. In 2004, the median ratio between land loss and family income $\left(b_{i} / I_{i}\right)$ was 17.0 percent. By comparison, in the re-calibrated 2018 economy, the median $b_{i} / I_{i}$ is 5.3 percent. From the baseline economy, we change $\mu_{b}$ so that the median $b_{i} / I_{i}$ is 5.3 percent. The effects of this change are reported in Table 10. Between 2004 and 2018, the percentage of rural households who operate farms falls substantially from 71.8 percent to 53.9 percent. As a

\footnotetext{
${ }^{8}$ Details regarding the re-calibration in 2018 are provided in Appendix D.
} 
Table 10: The Evolution of Frictions Over Time

\begin{tabular}{lrrr}
\hline & Baseline & $\begin{array}{r}\text { 2018 Land } \\
\text { Security }\end{array}$ & $\begin{array}{r}\text { 2018 Labor } \\
\text { Barriers }\end{array}$ \\
\hline Village households operating farms (\%) & 71.9 & 53.9 & 72.8 \\
Agricultural employment share among villagers (\%) & 56.6 & 53.2 & 57.2 \\
$\Delta$ Agricultural output (\%) & - & -0.2 & +0.8 \\
$\Delta$ Agricultural labor productivity (\%) & - & +6.2 & -0.2 \\
$\Delta$ Median log farm operator ability (\%) & - & +5.4 & -0.6 \\
$\Delta$ Non-agricultural output (\%) & - & +1.5 & +2.8 \\
$\Delta$ Real GDP per capita (\%) & & & +2.5 \\
Within-household selection in farming: & 56.0 & 58.6 & 56.0 \\
\% of farm operators with highest $s_{i j}$ &
\end{tabular}

Note: Statistics for the baseline 2004 economy and two counterfactuals with frictions at their 2018 value. We replace the level of land frictions $\mu_{b}$ such that the median $b_{i} / I_{i}$ matches that of the 2018 level (second column) and labor mobility frictions $\xi_{i j}^{r}$ and $\xi_{i j}^{u}$ to 2018 values (third column). The percentage of village households operating farms and the sectoral employment shares among villagers are in levels, while all other statistics are displayed as differences compared to the baseline 2004 economy.

result, agricultural labor productivity increases by 6.2 percent. This result suggests that land frictions in 2018 are much less severe compared to 2004, consistent with a literature emphasizing that land titling reforms in China have greatly alleviated frictions in the land market. ${ }^{9}$ Second, we change labor mobility barriers from 2004 to their 2018 values, and find that the agricultural employment share actually increases and that agricultural labor productivity declines slightly. This suggests that labor mobility barriers between agriculture and the non-agricultural sectors have deteriorated over our sample period.

The comparison in the evolution of land and labor frictions has important implications for our understanding of migration costs. Simply looking at migration data, we might infer on the basis of the reallocation of labor from agriculture to non-agriculture over time that migration costs have fallen. But looking at the distinct components of migration costs, we find that the reduction in migration cost arises exclusively from a reduction in land insecurity

\footnotetext{
${ }^{9}$ During the sample period (2004-2018), there are families that completely migrate to urban areas and hence are replaced in our sample. If these drop-out households are less likely to be engaged in farming before migration than newly introduced households, then our calculation underestimates the decline in the percentage of households who operate farms, and in turn, underestimates the improvement in land security over time.
} 
frictions rather than labor mobility barriers, the focus of a large literature. In fact, we find that residual labor mobility barriers have increased slightly over time.

\subsection{Land Security and Misallocation within Agriculture}

We now examine the effect of reforms in land market institutions that simultaneously eliminate the idiosyncratic farm distortions within agriculture and reduce the perceived income cost from losing access to rural land. Recall that idiosyncratic farm distortions $\tau_{i j}$ induce misallocation within agriculture. Much of the observed misallocation arises from implicit land-market distortions associated with an egalitarian distribution of land-use rights at the village level (Adamopoulos et al., 2021). In our framework, $b_{i}$ captures the perceived cost for village households of losing access to farmland, but does not directly affect operational farm size. We expect however that land insecurity, a feature of the land market institutions in China, affects both $\tau_{i j}$ and $b_{i}$.

To compare the effects of perceived income loss with that of idiosyncratic farm distortions and study their interaction, we implement an experiment from the baseline model that removes idiosyncratic farm distortions, that is, we set $\tau_{i j}=1$ for all individuals and households. We also examine the effect of a land security reform that eliminates the perceived income loss $\left(b_{i}=0\right)$ in the economy and eliminates the idiosyncratic farm-operation barriers. Note that while distortions associated with land insecurity and idiosyncratic farm distortions transmit through different channels, both distortions arise from the same broad land institution; hence, land reform is expected to have effects on both sources of distortions. Given that in practice, such a reform is unlikely to eliminate entirely both the perceived income loss and the farm distortions, our results capture an upper bound of these effects. Results of these two experiments are reported in Table 11, columns two and three, along with the land security experiment discussed previously.

Consistent with the findings in Adamopoulos et al. (2021), removing idiosyncratic distortions has a substantial positive effect on agricultural productivity. The striking finding 
is that land security substantially amplifies the productivity effects of eliminating misallocation within agriculture, in particular, agricultural labor productivity nearly doubles with land security compared to just eliminating idiosyncratic farm distortions (an increase in agricultural labor productivity of 430 percent compared with 224 percent with just removing idiosyncratic farm distortions). This result is significant since it illustrates the complementarity between the misallocation within agriculture and the misallocation across sectors and space that is generated by an egalitarian distribution of land with insecure property rights.

Table 11: Interaction between Land Security and Misallocation within Agriculture

\begin{tabular}{lrrrr}
\hline & Baseline & $\begin{array}{r}\text { Land } \\
\text { Security }\end{array}$ & $\begin{array}{r}\text { No Idiosyncratic } \\
\text { Farm Distortions }\end{array}$ & $\begin{array}{r}\text { + Land } \\
\text { Security }\end{array}$ \\
\hline Village households operating farms (\%) & 71.9 & 42.7 & 48.8 & 2.4 \\
Agr. employment share among villagers (\%) & 56.6 & 51.1 & 33.5 & 21.4 \\
$\Delta$ Agricultural output (\%) & - & -0.3 & +91.9 & +100.2 \\
$\Delta$ Agricultural labor productivity (\%) & - & +10.5 & +224.4 & +430.1 \\
$\Delta$ Median log farm operator ability (\%) & - & +10.6 & -16.0 & +161.3 \\
$\Delta$ Non-agricultural output (\%) & - & +2.3 & +7.1 & +10.6 \\
$\Delta$ Real GDP per capita (\%) & - & +1.9 & +14.3 & +18.1 \\
Within-household selection in farming: & & & & \\
\% of farm operators with highest $s_{i j}$ & 56.0 & 60.3 & 38.7 & 91.3 \\
\hline
\end{tabular}

Notes: Statistics of the baseline model for three counterfactual experiments: Land security $\left(b_{i}=0\right.$ for all $i)$, no idiosyncratic farm distortions $\left(\tau_{i j}=0\right)$, and both. Statistics for deviations $\Delta$ are from the baseline model.

The reason for the important quantitative interaction between land security and idiosyncratic farm distortions is two-fold. First, on the extensive margin, in an economy without idiosyncratic farm distortions, land security $\left(b_{i}=0\right)$ encourages the exit of relatively less productive farmers, resulting in a substantial increase of median log farm operator ability of 161.3 percent. By contrast, in the presence of misallocation in agriculture, land security $\left(b_{i}=0\right)$ does not necessarily feature strong selection in farming as implied by the modest increase in median log farm operator ability (10.6 percent). Second, on the intensive margin, land security without idiosyncratic farm distortions enables the reallocation of land from less to more productive farms, whereas with misallocation within agriculture the land re- 
allocation associated with mobility does not necessary flow to the most productive farms. Also note that eliminating idiosyncratic farm distortions in the presence of land insecurity substantially aggravates the misallocation of farming talent since only 38.7 percent of the farming households have the most talented operator. A reform of land institutions that improves land security and resource allocation within agriculture can attain a substantial increase in agricultural productivity due in part to improved selection within households.

\section{Robustness and Extension}

We evaluate our results using an alternative calibration of land security that draws on supplementary survey data we collected. We also extend the model to incorporate regional heterogeneity.

\subsection{Alternative Calibration of $b_{i}$}

Recall that $b_{i}$ captures a household's potential income loss if they lose their land. There are broadly two types of events in a village that can trigger land loss for households renting their land out (or that let it lie fallow): village land reallocations and village-wide land takings. Conceptually, this suggests that the probability of land loss can be represented by $p_{1} \times p_{2}$, where $p_{1}$ is the probability that either a land reallocation or land taking occurs in a village which affects a household's land, and $p_{2}$ denotes the probability that a village household then actually loses their land in the course of either of these events, and is not compensated for the loss. Multiplying then the probability of a land loss by the stream of income generated by the land provides an estimate of the household's potential loss.

In our supplementary survey, we find $p_{2}$ to be around $0.5{ }^{10}$ We need to estimate $p_{1}$. For land reallocations, typically all of the land in a village is affected. Between 1991-2003, a total of 155 reallocations occurred in our sample of 120 villages, implying an annual probability of

\footnotetext{
${ }^{10}$ The details are discussed in Appendix A.4.
} 
a land reallocation of 9.9 percent (155 events divided by 120 villages divided by 13 years). For land takings, over the period between 1991-2003, a total of 123 land taking events occurred, implying a probability of 7.9 percent. In the case of land takings, not all the land in a village is affected; on average, we find that approximately 4 percent of cultivated land is expropriated. We assign $p_{1}=p_{1}[$ reallocation $]+p_{1}$ [takings $]=0.099+0.079 \times 0.04=0.102$. The annual probability of land loss associated with not operating a farm is hence $p_{1} \times p_{2}=0.051$.

We estimate the value of land to be 3 times of household income. In our baseline model, the share of land in farm income is 0.4 . With farming the source of one-third of total family income in 2004, the agricultural revenue from land represents 0.133 of total household income. Using subjective discount rates ranging from 3 to 5 percent, and a time horizon of 30 years, the value of land relative to household income ranges from 2.7 to 4.4 . We take a value of 3 to be conservative. If we use a higher ratio, land insecurity would be quantitatively more important.

Our back-of-the-envelope calculation suggests that the value of $b_{i}$ should be $p_{1} \times p_{2} \times 3=$ 15.3 percent of household income. We choose $\mu_{b}$ so that the median of $b_{i}$ to household income ratio is 15.3 percent. Note that with this estimation strategy we no longer target the percentage of village households who operate farms, which in our baseline calibration identifies $\mu_{b}$. All other parameters are chosen to match the same set of moments as in the baseline calibration. The details of this alternative calibration are reported in Table D.4 in Appendix D.

Using this alternative calibration of $\mu_{b}$, we implement the same experiment that improves land security by setting $b_{i}=0$ for all households, and report the results in Table 12 . Using this alternative calibration of $\mu_{b}$, the percentage of village households operating farms is 69.9 percent compared with 71.9 percent in the data (note that in our baseline calibration, $\mu_{b}$ is chosen to match this moment). Land security reduces the share of village households operating farms by 29.0 percentage points, roughly the same the 29.1 percentage points with the baseline calibration. The improvement in agricultural labor productivity of 12.2 percent 
is also similar to the 10.5 percent in the baseline. The robustness of our results to this alternative calibration of land loss provides confidence on the quantitative importance of land security on mobility decisions.

Table 12: The Role of Land Security, Alternative Calibration of $\mu_{b}$

\begin{tabular}{lccc}
\hline & Alternative & Land & No Labor \\
& Calibration & Security & Barriers \\
\hline Village households operating farms (\%) & 69.9 & 40.9 & 47.6 \\
Agricultural employment share among villagers (\%) & 55.3 & 49.1 & 45.1 \\
$\Delta$ Agricultural output (\%) & - & -0.3 & -6.8 \\
$\Delta$ Agricultural labor productivity (\%) & - & +12.2 & +14.2 \\
$\Delta$ Median log farm operator ability (\%) & - & +11.0 & +3.9 \\
$\Delta$ Non-agricultural output (\%) & - & +2.5 & +9.3 \\
$\Delta$ Real GDP per capita (\%) & - & +2.0 & +5.6 \\
\hline
\end{tabular}

Notes: Model statistics for alternative calibration of $\mu_{b}$ and the counterfactual experiments of land security $\left(b_{i}=0\right.$ for all $\left.i\right)$ and no labor mobility barriers $\left(\xi_{i j}^{r}=\xi_{i j}^{u}=0\right)$. The percentage of village households operating farms and the sectoral employment shares among villagers are in levels, while all other moments are displayed as differences compared to the calibrated model.

We can follow the same strategy to also assess the evolution of land security over time. Our supplementary survey data reveal that the likelihood of land reallocation declines substantially over time due to policy changes, most notably, the 1998 Land Management Law (LML) and the 2002 Rural Land Contracting Law (RLCL), which fix land allocations for 30 years. The estimated annual probability of land reallocation falls to only 0.9 percent after 2004. Given that the frequency of land reallocations drives our alternative calculation of $b_{i}$, their decline is consistent with our calibration results and the fall in the importance of land loss $b_{i}$ over time. As for land takings, the annual probability of a land taking after 2003 (7.3 percent) is similar to that before, however more land (9.4 percent) is involved. As a result, land takings becomes more important.

Estimating land loss $b_{i}$ for 2018 using this alternative strategy has some limitations. For instance, even with the decline in the frequency of land reallocations, it may take time for farmers to update their beliefs regarding land tenure security. There is also uncertainty in forecasting future policy changes. Moreover, for land takings, only a small amount of land 
is affected in each village, but there may be uncertainty over which plots may be affected; hence, the perceived insecurity could also be higher. Finally, in line with Chinese law, our calculations are based on the agricultural value of land, however compensation for lost land may also reflect rising non-agricultural values and thus be substantially higher.

\subsection{Village Heterogeneity}

Rich heterogeneity exists across villages in China. We assess how land security and labor mobility barriers differ across one dimension, proximity to urban centers. We divide villages into two groups: (a) Peri-urban and (b) Remote, according to a village's location indicator. This classification implies that 37 percent of our farm-household observations are in Peri-urban villages and the remaining in Remote villages for the year 2004. This division highlights the observation that households in the Peri-urban areas have better access to opportunities in the rural and urban non-agricultural sectors; thus, labor mobility barriers are likely to be lower.

For each region, we re-calibrate the model. The aggregate target moments remain the same, while micro data moments are calculated using observations from each set of villages. In each recalibration, we assume that all villages in the economy are only Peri-urban or Remote. The resulting calibrated parameter values are reported in Table D.4 in Appendix D. Comparing the two sets of villages, Peri-urban villages feature a substantially lower fraction of households operating farms and a lower share of individuals employed in agriculture. These observations suggest that the off-farm opportunities are more appealing to individuals in the Peri-urban region, or that land insecurity and mobility frictions are less severe. We now take a deeper look at land security and labor mobility barriers for Peri-urban and Remote regions.

Land insecurity is substantially less severe in the Peri-urban than in Remote villages. The median $b_{i} / I_{i}$ ratio is 10.6 percent in Peri-urban compared to 20.5 percent in the Remote region. Providing land security $\left(b_{i}=0\right)$ in the Peri-urban area reduces the percentage of 
Table 13: Regional Heterogeneity

\begin{tabular}{|c|c|c|c|}
\hline \multicolumn{4}{|l|}{ (a) Peri-urban } \\
\hline & $\begin{array}{r}\text { Baseline } \\
\text { Calibration }\end{array}$ & $\begin{array}{r}\text { Land } \\
\text { Security }\end{array}$ & $\begin{array}{r}\text { No Labor } \\
\text { Barriers }\end{array}$ \\
\hline Village households operating farms (\%) & 53.9 & 33.5 & 35.9 \\
\hline Agrricultural employment share among villagers (\%) & 44.4 & 40.6 & 35.9 \\
\hline$\Delta$ Agricultural output $(\%)$ & - & -0.6 & -7.7 \\
\hline$\Delta$ Agricultural labor productivity $(\%)$ & - & +8.7 & +14.2 \\
\hline$\Delta$ Median log farm operator ability (\%) & - & +9.9 & +6.3 \\
\hline$\Delta$ Non-agricultural output $(\%)$ & - & +1.5 & +6.3 \\
\hline$\Delta$ Real GDP per capita $(\%)$ & - & +1.2 & +3.9 \\
\hline \multicolumn{4}{|l|}{ (b) Remote } \\
\hline & $\begin{array}{r}\text { Baseline } \\
\text { Calibration }\end{array}$ & $\begin{array}{r}\text { Land } \\
\text { Security }\end{array}$ & $\begin{array}{r}\text { No Labor } \\
\text { Barriers }\end{array}$ \\
\hline Village households operating farms (\%) & 75.9 & 46.1 & 58.8 \\
\hline Agricultural employment share among villagers (\%) & 61.9 & 55.6 & 53.5 \\
\hline$\Delta$ Agricultural output $(\%)$ & - & +0.1 & -6.0 \\
\hline$\Delta$ Agricultural labor productivity $(\%)$ & - & +11.5 & +8.7 \\
\hline$\Delta$ Median log farm operator ability (\%) & - & +12.6 & +1.4 \\
\hline$\Delta$ Non-agricultural output $(\%)$ & - & +2.6 & +7.1 \\
\hline$\Delta$ Real GDP per capita $(\%)$ & - & +2.2 & +3.8 \\
\hline
\end{tabular}

Note: Statistics for the baseline estimated model versus our two counterfactual experiments, land security $\left(b_{i}=0\right.$ for all $\left.i\right)$ and no labor mobility barriers $\left(\xi_{i j}^{r}=\xi_{i j}^{u}=0\right)$. Panel (a) shows results for the Periurban area and panel (b) for the remote area. The percentage of village households operating farms and the sectoral employment shares among villagers are in levels, while all other statistics are displayed as differences compared to the baseline model.

village households operating farms by 20.4 percentage points and raises agricultural labor productivity by 8.7 percent. As expected, the effects are even larger in the Remote villages - the percentage of village households operating farms drops by 29.8 percentage points and agricultural labor productivity increases by 11.5 percent.

The comparison of labor mobility barriers is a bit more complicated. Labor mobility barriers to the rural non-agricultural sector are substantially lower in Peri-urban compared to Remote. This is reflected in the estimated parameters $\mu_{r}=0.510$ and $\mu_{r}^{o}=0.862$ for Periurban compared with $\mu_{r}=0.852$ and $\mu_{r}^{o}=1.156$ for Remote. In contrast, labor mobility barriers to the urban non-agricultural sector are slightly higher for Peri-urban. Removing 
all labor mobility barriers has slightly larger effects for Remote in terms of non-agricultural output and real GDP per capita, but similar effects for the percentage of village households operating farms and agricultural employment share among villagers.

A distinct feature of China's economic growth is the prominence of township and village entreprises (TVE's). These TVE's are often located in towns and Peri-urban areas providing off-farm opportunities to villagers (Brandt and Zhu, 2010). Since TVE's are part of the rural non-agricultural sector in our model, it is unsurprising that labor mobility barriers to the local non-agricultural sector are lower for villagers living in Peri-urban areas. The fact that Peri-urban and Remote villagers face similar barriers to the urban non-agricultural sector indicates that the barriers may largely arise from factors other than geographical distances.

There may be two reasons for why land frictions could be lower in the Peri-urban area. First, agriculture is less important for Peri-urban villagers, reflected in the lower share of households operating farms and in the lower agricultural employment share, as individuals have more off-farm opportunities or they face lower labor mobility barriers. Hence, land demand is lower in Peri-urban villages and village leaders are thus subject to less lobbying pressure by villagers to reallocate land. This may explain why the land loss arising from land redistribution is lower in the Peri-urban area. Second, Peri-urban villages are closer to cities/towns and hence village leaders may be under more efficient supervision of local government, resulting in less uncompensated expropriation.

\section{Conclusions}

We have developed a unified framework to study jointly the effect of land security and other labor mobility frictions on agricultural productivity, structural change, and economic development. A key ingredient of our model is that we allow for selection of individuals within families, across sectors, and across space. This framework along with the rich heterogeneity in the panel data for China allow us to quantify the role and impact of land security and 
other labor mobility frictions over time.

We find that in 2004 effective migration costs are high, with land security and all other labor mobility frictions playing an equal role in these costs. By 2018 however, overall migration costs have dropped, with all of the decline accounted for by improved land security. In fact, labor mobility costs unrelated to land institutions increased slightly between 2004-2018. This implies that attributing the significant increase in migration we observe to a drop in labor mobility barriers is misleading. We also find that farm distortions within agriculture, interacting with selection, amplify the positive effect of land security on productivity.

Our findings have important implications for development policy. Farm-level distortions within agriculture and land insecurity that deters migration out of agriculture stem from the same set of weak property rights over rural land. Since 2003, there have been significant reforms in China that have strengthened household property rights in land. Our results are consistent with land policy having been central to China's structural change and agricultural productivity growth over the last two decades. While there have been reforms since the early 2000s to migration policy, particularly the hukou registration system, these changes have not had an impact on out-migration from agriculture, structural change and growth. The implication is that there are effective labor mobility barriers facing rural households that are still high. This could be due to a non-uniform reform or implementation of the migration policy (e.g., it is actually more difficult to move to the coastal mega-cities), or due to other factors that deter living in the cities such as higher housing prices. Our results indicate that there is scope for further agricultural productivity growth and structural change from reductions in other direct and indirect labor mobility barriers. As a result, future policy reforms that reduce effective rural-urban migration costs can have large welfare benefits.

We have focused on the interaction between land insecurity and migration decisions. Many other factors also affect structural transformation and rural-urban migration and could have interesting interactions with insecure land tenure, including international trade (Tombe and Zhu, 2019), capital-labor substitution (Chen, 2020a,b), choices between food crops and 
cash crops (Adamopoulos and Restuccia, 2020), and local entry barriers of establishments

(Brandt et al., 2020). We leave the study of the interaction of these factors with insecure land tenure for future research.

\section{References}

Acemoglu, D., Johnson, S., and Robinson, J. A. (2001). The colonial origins of comparative development: An empirical investigation. American Economic Review, 91(5):1369-1401.

Acemoglu, D., Johnson, S., and Robinson, J. A. (2005). Institutions as a fundamental cause of long-run growth. Handbook of Economic Growth, 1(A):385-472.

Adamopoulos, T., Brandt, L., Leight, J., and Restuccia, D. (2021). Misallocation, selection, and productivity: A quantitative analysis with micro data from China. Econometrica, forthcoming.

Adamopoulos, T. and Restuccia, D. (2014). The size distribution of farms and international productivity differences. American Economic Review, 104(6):1667-1697.

Adamopoulos, T. and Restuccia, D. (2020). Land reform and productivity: A quantitative analysis with micro data. American Economic Journal: Macroeconomics, 12(3):1-39.

Alvarez, J. A. (2020). The agricultural wage gap: Evidence from brazilian micro-data. American Economic Journal: Macroeconomics, 12(1):153-73.

Asher, S. and Novosad, P. (2020). Rural roads and local economic development. American Economic Review, 110(3):797-823.

Benjamin, D. and Brandt, L. (2002). Property rights, labour markets, and efficiency in a transition economy: The case of rural China. Canadian Journal of Economics, 35(4):689716.

Benjamin, D., Brandt, L., and Giles, J. (2005). The evolution of income inequality in rural china. Economic Development and Cultural Change, 53(4):769-824.

Bento, P. and Restuccia, D. (2017). Misallocation, establishment size, and productivity. American Economic Journal: Macroeconomics, 9(3):267-303.

Brandt, L., Huang, J., Li, G., and Rozelle, S. (2002). Land rights in rural china: Facts, fictions and issues. The China Journal, (47):67-97.

Brandt, L., Kambourov, G., and Storesletten, K. (2020). Barriers to entry and regional economic growth in China. Working Paper.

Brandt, L., Tombe, T., and Zhu, X. (2013). Factor market distortions across time, space and sectors in china. Review of Economic Dynamics, 16(1):39-58. 
Brandt, L. and Zhu, X. (2010). Accounting for China's growth. Working Paper.

Brueckner, J. K. and Lall, S. V. (2015). Cities in developing countries: fueled by rural-urban migration, lacking in tenure security, and short of affordable housing. Handbook of regional and urban economics, 5:1399-1455.

Bryan, G., Chowdhury, S., and Mobarak, A. M. (2014). Underinvestment in a profitable technology: The case of seasonal migration in bangladesh. Econometrica, 82(5):16711748.

Bryan, G. and Morten, M. (2019). The aggregate productivity effects of internal migration: Evidence from indonesia. Journal of Political Economy, 127(5):2229-2268.

Caliendo, L., Dvorkin, M., and Parro, F. (2019). Trade and labor market dynamics: General equilibrium analysis of the china trade shock. Econometrica, 87(3):741-835.

Chan, K. W. (2019). China's hukou system at 60: Continuity and reform. In Handbook on urban development in China. Edward Elgar Publishing.

Chan, K. W. and Zhang, L. (1999). The hukou system and rural-urban migration in china: Processes and changes. The China Quarterly, (160):818-855.

Chari, A., Liu, E. M., Wang, S.-Y., and Wang, Y. (2021). Property rights, land misallocation, and agricultural efficiency in china. The Review of Economic Studies, 88(4):1831-1862.

Chen, C. (2017). Untitled land, occupational choice, and agricultural productivity. American Economic Journal: Macroeconomics, 9(4):91-121.

Chen, C. (2020a). Capital-skill complementarity, sectoral labor productivity, and structural transformation. Journal of Economic Dynamics and Control, 116.

Chen, C. (2020b). Technology adoption, capital deepening, and international productivity differences. Journal of Development Economics, 143:102388.

Chen, C., Restuccia, D., and Santaeulalia-Llopis, R. (2021). The effects of land markets on resource allocation and agricultural productivity. Review of Economic Dynamics, forthcoming.

de Brauw, A. and Giles, J. (2018). Migrant labor markets and the welfare of rural household in the developing world: Evidence from China. The World Bank Economic Review, 32(1):1-18.

de Janvry, A., Emerick, K., Gonzales-Navarro, M., and Sadoulet, E. (2015). Delinking land rights from land use: Certification and migration in Mexico. American Economic Review, 105.

Giles, J. and $\mathrm{Mu}$, R. (2018). Village political economy, land tenure insecurity, and the rural to urban migration decision: Evidence from China. American Journal of Agricultural Economics, 100(2):521-544. 
Glaeser, E. L. and Lu, M. (2018). Human capital externalities in China. Working Paper.

Gollin, D., Lagakos, D., and Waugh, M. E. (2014). Agricultural productivity differences across countries. American Economic Review: Papers and Proceedings, 104(5):165-170.

Gollin, D., Parente, S. L., and Rogerson, R. (2002). The role of agriculture in development. American Economic Review: Papers and Proceedings, 92(2):160-164.

Gottlieb, C. and Grobovšek, J. (2019). Communal land and agricultural productivity. Journal of Development Economics, 138:135-152.

Hamory, J., Kleemans, M., Li, N. Y., and Miguel, E. (2021). Reevaluating agricultural productivity gaps with longitudinal microdata. Journal of the European Economic Association, 19(3):1522-1555.

Hobijn, B., Schoellman, T., and Q., A. V. (2018). Structural transformation by cohort. Working Paper.

Hsieh, C.-T. and Klenow, P. J. (2009). Misallocation and manufacturing TFP in China and India. Quarterly Journal of Economics, 124(4):1403-1448.

Kung, J. K.-s. and Liu, S. (1997). Farmers' preferences regarding ownership and land tenure in post-mao china: unexpected evidence from eight counties. The China Journal, (38):3363.

Lagakos, D., Marshall, S., Mobarak, A. M., Vernot, C., and Waugh, M. E. (2020). Migration costs and observational returns to migration in the developing world. Journal of Monetary Economics, forthcoming.

Lagakos, D. and Waugh, M. E. (2013). Selection, agriculture, and cross-country productivity differences. American Economic Review, 103(2):948-980.

Morten, M. and Oliveira, J. (2018). The effects of roads on trade and migration: Evidence from a planned capital city. Working Paper.

Munshi, K. and Rosenzweig, M. (2016). Networks and misallocation: Insurance, migration, and the rural-urban wage gap. American Economic Review, 106(1):46-98.

Ngai, L. R., Pissarides, C. A., and Wang, J. (2019). China's mobility barriers and employment allocations. Journal of European Economic Association, 17(5):1617-1653.

Restuccia, D. (2019). Misallocation and aggregate productivity across time and space. Canadian Journal of Economics/Revue canadienne d'économique, 52(1):5-32.

Restuccia, D., Yang, D. T., and Zhu, X. (2008). Agriculture and aggregate productivity: A quantitative cross-country analysis. Journal of Monetary Economics, 55(2):234-250.

Schoellman, T. (2020). Comment on "migration costs and observational returns to migration in the developing world". Journal of Monetary Economics, forthcoming. 
Song, Z., Storesletten, K., and Zilibotti, F. (2011). Growing like China. American Economic Review, 101(1):196-233.

Tombe, T. and Zhu, X. (2019). Trade, migration, and productivity: A quantitative analysis of china. American Economic Review, 109(5):1843-72.

Wu, W. and You, W. (2020). The welfare implications of internal migration restrictions: Evidence from China. Working Paper.

Yao, W. and Zhu, X. (2020). Structural change and aggregate employment fluctuations in China. International Economic Review, forthcoming.

Zhou, C., Liang, Y., and Fuller, A. (2021). Tracing agricultural land transfer in china: Some legal and policy issues. Land, 10(1):58. 


\section{Appendix}

\section{A Data}

We draw on data from the National Fixed Point Survey carried out by the Research Center for Rural Economy (RCRE), Chinese Ministry of Agriculture. For each farm household, we have information on farm inputs and outputs in physical quantities and prices, together with individual-level data on labor supply and wage earnings. The survey was first conducted in 1986, but it was only in 2003 that individual-level labor supply data were collected. Below we describe in detail how we construct our empirical moments.

\section{A.1 Farm-Household Statistics}

We follow closely Adamopoulos et al. (2021) in our use of household panel data to construct estimates of farm outputs, inputs, and farm-level TFP and TFPR.

Gross output.- We focus on the cropping sector, and exclude sideline agricultural activity (animal husbandry, aquaculture, and forestry). Gross output of each crop is reported in physical quantity. To calculate real gross output at the farm level, we aggregate over all crops using common and constant prices of crops. For each household that sells to the market, we observe the reported quantities and revenues for each crop, which allows estimates of prices (unit values). For each crop, we calculate the median price over all households in 2003. By 2003, quota sales to the government at below market (quota) prices were very small, and thus do not distort our measures of real output.

Labor.- Our data record labor input by crop for each family farm. Total labor input is the sum of labor input in all crops supplied by both the household and hired labor, measured in days.

Land.-Land input is calculated as the sum of cultivated area of crops and orchards. Note that we have information on sown area but we choose not to use it as our measure of 
land since a plot of land could be used multiple times per year.

Intermediate inputs.-The value of intermediate inputs is calculated as the sum of expenditure on fertilizer, seeds, diesel fuel, pesticides, etc. We observe both quantities and expenditures on each input, and estimate the real value of intermediate input using common and constant prices across all observations in 2003.

Value added.-The value added of each farm is calculated as the difference between the real value of gross crop output and that of intermediate inputs. We calculate both the nominal value added with local and current prices and real value added using common and constant prices.

Farm productivity.-We separately estimate revenue productivity (TFPR) and quantity productivity (TFPQ) for farms. In particular, we define TFPR and TFPQ as

$$
\mathrm{TFPR}_{i}=\frac{y_{i}}{l_{i}^{\theta} n_{i}^{1-\theta}}, \quad \mathrm{TFPQ}_{i}=\frac{y_{i}}{\left(l_{i}^{\theta} n_{i}^{1-\theta}\right)^{\gamma}}
$$

where $y_{i}$ is real farm value added, $n_{i}$ is farm labor input, and $l_{i}$ is operated land. To address potential measurement errors and transitory shocks such as rainfall and health shocks, we follow Chen et al. (2021). We first estimate farm productivity $s_{i t}$ for each year as the residual from the production function:

$$
s_{i t}=\left(\frac{y_{i t}}{\left(l_{i t}^{\theta} n_{i t}^{1-\theta}\right)^{\gamma}}\right)^{\frac{1}{1-\gamma}}
$$

We then estimate the permanent component of $s_{i t}$ by extracting household fixed effects from a panel regression:

$$
\log s_{i t}=\beta_{t} t+\log \tilde{s}_{i}+\varepsilon_{i t}^{s}
$$

Using the estimated farm fixed effect $\tilde{s}_{i}$, we reconstruct farm output using the production function:

$$
\tilde{y}_{i t}=A \tilde{s}_{i}^{1-\gamma}\left(l_{i}^{\theta} n_{i}^{1-\theta}\right)^{\gamma}
$$


We then use $\tilde{y}_{i t}$ to estimate farm TFPR and farm TFP, the dispersion of the log of both measures, and the correlation between them, which we use in our calibration.

\section{A.2 Individual Statistics}

Households have unique identifiers that allow us to link them over survey years, however there are not individual IDs. We match individuals within a household using information on age, gender, education and their relationship with the head of the household, which allows us to identify uniquely individuals within each household in 99 percent of the cases. We drop the remaining one percent that we cannot link over time. Our individual-level data set is comprised of all working individuals between the ages of 16 and 65 .

Individual labor supply.-We calculate labor supply in days for three types of work: agriculture, rural non-agriculture, and urban non-agriculture. Rural and urban employment are differentiated on the basis of location. Employment in non-agriculture within the same county as the household resides is classified as rural non-agriculture, while employment outside the county is urban non-agriculture.

Individual wage rate.-We calculate the daily wage rate for rural and urban non-agriculture separately by dividing labor income by labor days. For rural non-agricultural employment, labor income is only recorded for labor supply outside of village/town but within county. We assume that wage rate within village/town is the same as that outside of village/town but within county.

Farming households.-Almost all households in our data have small family plots. To distinguish between farming and non-farming households, we impose minimum thresholds on cultivated area, days supplied to farming, and gross farm revenue. We require cultivated area to be larger than one mu (1/6th of an acre), labor supply of the farm operator (defined below) to be more than 60 days, and for gross revenue to be more than 1000 yuan. These thresholds imply that $70.4 \%$ of households farmed in 2004 .

Farm operator.- In our model, we distinguish between farm operators and agricultural 
workers. In the survey, household members are explicitly asked: "Are you the main decision maker of your family?" We leverage this information to assign an individual within the household as the operator, in addition to requiring all operators to supply at least 60 days to agriculture. If only one individual within the household answers "yes", then this individual is assigned to be the operator. In 2004, 34.4\% of all household observations fit this case (or $48.9 \%=34.4 / 70.4$ of farming households). If more than one individual answers "yes" (or no one does), we select the household member with the greatest labor supply to agriculture. In the case of a tie, we pick the person with the smallest number of days supplied to non-agriculture. Combined, these case represent an additional 29.1\% of all household observations, or $41.3 \%=29.1 / 74.4$ of farming households. If there continue to be ties, we select the individual that is male, followed by the male that is oldest.

Occupation of individuals.-We drop from our analysis all individuals that are in school and those that work less than 10 days in any sector. We classify all other individuals into one of the following categories: (1) farm operator (as defined above), (2) full-time agricultural worker, (3) full-time rural non-agricultural worker, (4) full-time urban nonagricultural worker, (5) part-time agricultural and rural non-agricultural worker, and (6) part-time agricultural and urban non-agricultural worker. A very small number of individuals (less than $2 \%$ ) work in both rural and urban non-agricultural sectors, which we classify into category (6).

Cohorts.-We classify an individual as old if they are between the ages of 45 and 65, and young individual if they are 16 to 44 .

\section{A.3 Aggregate Moments}

Employment series.-The statistical yearbook of the NBS provides a decomposition of employment between rural and urban regions. Following Brandt and Zhu (2010) and Yao and Zhu (2020), agricultural employment is defined to be equal to total rural employment minus employment in township and village enterprises (TVE's) and private and family-run 
enterprises. Employment in TVE's and private and family-run enterprises is then the rural non-agricultural employment in our model. Urban employment maps into the employment of our urban non-agricultural sector. We denote the economy-wide employment shares as $s_{a}, s_{r}$, and $s_{u}$.

Household accounting.-We have three different types of households in our model: village households who choose to operate farms and decide between agriculture and non-agriculture, and rural non-agricultural (township) households and urban non-agricultural households who can only work in the rural or urban non-agricultural sector, respectively. Their shares are denoted as $m_{a}, m_{r}$, and $m_{u}$. We further denote the agricultural, rural-non-agricultural, and urban non-agricultural employment share among village households as $s_{a}^{v}, s_{r}^{v}$, and $s_{u}^{v}$.

Since only village households work in agriculture, the share of village households is:

$$
m_{a}=s_{a} / s_{a}^{v}
$$

The measures of township and urban households are then given by

$$
m_{r}=s_{r}-s_{r}^{v} m_{a}, \quad m_{u}=s_{u}-s_{u}^{v} m_{a}
$$

After 2013, the NBS no longer provides measures of TVE employment; hence, we cannot calculate employment shares in the same fashion. We use an alternative strategy to estimate the size of these three types of households, making a linear projection for the relative size of village households $\left(m_{a}\right)$ for 2014 onward. We then calculate the economy-wide agricultural employment share as:

$$
s_{a}=s_{a}^{v} m_{a}
$$

Rural non-agricultural employment $s_{r}$ is then rural employment from NBS net of agricultural employment $s_{a}$, while urban non-agricultural employment $s_{u}$ is simply the urban employment 
from NBS. The shares of township and urban households are calculated in the same way:

$$
m_{r}=s_{r}-s_{r}^{v} m_{a}, \quad m_{u}=s_{u}-s_{u}^{v} m_{a} .
$$

\section{A.4 Information on Land Insecurity}

Households that rent out their land are at risk of losing their land through two mechanisms: land reallocations and land expropriations by the state for non-agricultural use. In the case of a village reallocation, land was taken back from households by the village, and redistributed anew to village households. At risk for a household was the discounted present value of a household's land in farming. In the case of a land taking, at risk was the compensation households were entitled to in the event of a land taking. For farmland, compensation was tied to the returns to land in agriculture.

The law governing the HRS provided secure use rights over cultivated land for 15 years, nonetheless, village officials often reallocated village land among households before the term expired (Benjamin and Brandt, 2002). In the late 1990s and early 2000s, the State Council began to promote restrictions on land reallocations through the 1998 Land Management Law (LML) and the 2002 Rural Land Contracting Law (RLCL). Under the RLCL, household land use rights were also extended an additional 30 years.

We draw on two separate supplementary surveys undertaken with RCRE, the first in 2004 that covers the period between 1991 and 2003, and the second in 2018 that covers the period from 2003-2018, to capture changes in land tenure security resulting from reallocations and land takings. Both surveys covered 120 villages. In Table A.1, we provide summary information on the number, frequency, and thus the probability of a reallocation, and the same for land taking in a village. Between 1991-2003, a total of 155 reallocations were carried out, or a reallocation in a village every 10.9 years. This implies a probability of a reallocation in a village in any given year of $9.9 \% .{ }^{11}$ By contrast, the 2018 survey reveal

\footnotetext{
${ }^{11}$ There are some differences between villages, however. In 31/120 villages, there were no reallocations; in
} 
Table A.1: Summary of Frequency of Reallocations and Takings

\begin{tabular}{rccc}
\hline \multicolumn{4}{c}{ (a) Land Reallocations } \\
Period & Number & Number per year & Probability \\
\hline Survey, 2004: & & & \\
$1991-1999$ & 140 & 15.6 & $13.0 \%$ \\
$2000-2003$ & 15 & 3.8 & $3.1 \%$ \\
$1991-2003$ & 155 & 11.9 & $9.9 \%$ \\
Survey, 2018: & & & \\
$2003-2017$ & 16 & 1.1 & $0.9 \%$ \\
\hline
\end{tabular}

\begin{tabular}{lccccc}
\hline & \multicolumn{4}{c}{ (b) Land Takings } \\
Period & Number & Number per year & Probability & Land (Ha) & Households \\
\hline $\begin{array}{r}\text { Survey, 2004: } \\
\text { 1991-2003 }\end{array}$ & 123 & 9.5 & $7.9 \%$ & 581.6 & 11,076 \\
$\begin{array}{r}\text { Survey, 2018: } \\
2003-2017\end{array}$ & 123 & 8.2 & $7.3 \%$ & $1,433.0$ & 12,881 \\
\hline
\end{tabular}

Notes: Probability is calculated as the number of events per year divided by the number of villages (120) in our sample. For land takings, not all land/households in a village are involved. We hence report the measure of land and households involved in land taking events.

that only 16 reallocations were undertaken between 2003 and 2018, implying a probability of a reallocation in a village in any given year of less than one percent, or a reallocation every 100 years in a village. Consistent with the aims of the LML and RLCL, and data from other surveys (Brandt et. al., 2017), the two surveys suggest a marked decline in the likelihood of land reallocations. Moreover, after 2003, a majority of the reallocations were tied to land-takings and a redistribution of remaining land among households.

We report the same information with respect to land takings in the bottom half of the table. Based on the 2004 survey, we observe 123 land-takings between 1991-2003, which implies a land-taking in a village every 12.7 years. A typical land-taking over this period covered 4.7 hectare of land and affected 90 households. The 2018 survey suggests a similar frequency in land-takings, however the amount of land that was involved was almost two and a half times larger. There was also a modest increase in the number of households affected.

An important message from the summary is that up through 2003, reallocations and land$59 / 120$ there was a single reallocation and in 30/120 there were 2 or more. 
takings both contributed to the risk of land loss. After 2003, the risks fell with improved land tenue security associated with the reduction in land reallocations.

Table A.2: Likelihood that a Household Retains Land

\begin{tabular}{|c|c|c|c|c|c|c|}
\hline & \multicolumn{6}{|c|}{ (a) At the end of contract period } \\
\hline & \multicolumn{3}{|c|}{ Land is fallowed } & \multicolumn{3}{|c|}{ Land is rented out } \\
\hline & \multicolumn{2}{|c|}{ Family in village } & \multirow{2}{*}{$\begin{array}{l}\text { Family } \\
\text { outside }\end{array}$} & \multicolumn{2}{|c|}{ Family in Village } & \multirow{2}{*}{$\begin{array}{l}\text { Family } \\
\text { outside }\end{array}$} \\
\hline & Working & Non-working & & Working & Non-working & \\
\hline Shanxi & 39.9 & 47.7 & 21.7 & 58.3 & 61.9 & 53.3 \\
\hline Jilin & 44.1 & 36.8 & 25.7 & 84.4 & 86.0 & 64.1 \\
\hline Jiangsu & 34.1 & 33.2 & 21.6 & 63.0 & 63.0 & 53.5 \\
\hline Zhejiang & 71.4 & 69.4 & 68.7 & 80.7 & 80.7 & 80.7 \\
\hline Anhui & 57.2 & 55.8 & 36.8 & 85.2 & 85.7 & 64.7 \\
\hline Henan & 40.3 & 34.8 & 31.2 & 41.1 & 38.6 & 28.0 \\
\hline Hunan & 63.2 & 63.7 & 53.9 & 90.2 & 90.2 & 79.4 \\
\hline Guangdong & 61.4 & 59.9 & 58.6 & 71.1 & 73.2 & 77.8 \\
\hline Sichuan & 47.3 & 46.6 & 23.7 & 69.2 & 69.2 & 49.0 \\
\hline Gansu & 43.5 & 54.4 & 24.3 & 63.3 & 64.5 & 29.0 \\
\hline Average & 50.3 & 50.2 & 36.6 & 70.7 & 71.3 & 58.0 \\
\hline
\end{tabular}

(b) Before the end of contract period

Land is fallowed

Land is rented out

\begin{tabular}{lcccccc} 
& \multicolumn{2}{c}{ Family in village } & Family & \multicolumn{2}{c}{ Family in village } & Family \\
& Working & Non-working & outside & Working & Non-working & outside \\
\hline Shanxi & 45.3 & 55.4 & 28.5 & 61.7 & 64.0 & 60.0 \\
Jilin & 51.3 & 53.7 & 45.2 & 87.2 & 87.2 & 85.2 \\
Jiangsu & 61.2 & 60.3 & 47.2 & 89.0 & 88.3 & 87.0 \\
Zhejiang & 97.5 & 96.3 & 92.7 & 100.0 & 100.0 & 100.0 \\
Anhui & 70.9 & 66.2 & 50.9 & 92.9 & 92.7 & 91.0 \\
Henan & 50.6 & 45.5 & 40.8 & 54.1 & 46.7 & 38.3 \\
Hunan & 83.2 & 89.8 & 79.5 & 98.5 & 97.0 & 97.2 \\
Guangdong & 69.1 & 71.2 & 74.1 & 80.4 & 82.5 & 95.0 \\
Sichuan & 69.0 & 68.6 & 48.2 & 89.3 & 89.9 & 87.4 \\
Gansu & 53.0 & 43.0 & 31.5 & 57.5 & 70.3 & 65.0 \\
Average & 65.1 & 65.0 & 53.8 & 70.7 & 81.8 & 80.6 \\
\hline
\end{tabular}

Notes: The table reports the likelihood that a household retains land if it is fallowed or rented out. Numbers are in percentages.

A piece of information that is critical to our assessment of property rights is households' perceptions of land security if they rent their land out. Households were asked the likelihood that they retained their land at either end of the contract period or within the contract 
period if they rented out under the following cases: (1) family members were working in the village; (2) family members were working outside the village, but older household members and children are still in the village; and (3) the entire family was working and living in the city.

In Table A.2, we summarize this information at the provincial level for the 10 provinces for which we have information. Over all households, 42 (63) percent believed they would lose their land if they rented it out (let it lie fallow) and the entire family moved to the city. The percentage falls to 30 percent if they have family members still living and working in the village. Slightly lower probabilities are tied to the same before if this occurs within the contract period. We hence assign the probability of retaining land without operating farms to be 0.5 in Section 7.1. We highlight that this tables report the perceptions surveyed in 2018, while the perceived likelihood of losing land in 2004 should be higher. In that regard, our choice of the probability of 0.5 is conservative. Note the significant differences between villages, with property rights much more secure in Zhejiang, Guangdong and Henan compared to the other provinces.

We asked the same set of questions to village leaders. Without exception, and with only minor differences between provinces, village leaders reported that property rights were much more secure, with the risk of losing land in the case of rental very small.

\section{B Estimation}

Given the parameterization of abilities and distortions, there are a total of 32 parameters to be determined in our model: 7 parameters of the ability distribution $\left(\sigma_{s}^{H}, \sigma_{s}^{I}, \sigma_{h}^{H}, \sigma_{h}^{I}, \lambda\right.$, $\mu_{s}^{y}$, and $\left.\mu_{h}^{y}\right) ; 9$ parameters of distortions; 2 parameters of idiosyncratic farm distortions $(\zeta$ and $\left.\sigma_{\tau}\right) ; 5$ parameters of the labor mobility barrier $\left(\mu_{r}, \mu_{r}^{o}, \mu_{u}, \mu_{u}^{o}\right.$, and $\left.\sigma_{\xi}\right) ; 2$ parameters of the land insecurity friction $\left(\mu_{b}\right.$ and $\left.\sigma_{b}\right) ; 2$ parameters of utility $(\phi$ and $\bar{a}) ; 4$ parameters of part-time labor supply $\left(\kappa, \nu, c^{r}\right.$, and $\left.c^{u}\right) ; 5$ parameters of technology $\left(\gamma, \theta, A, A_{r}\right.$, and $\left.A_{u}\right)$; 
and 5 parameters on endowments $\left(J, N_{r}, N_{u}, B\right.$, and $\left.p_{o}\right)$.

Out of these 32 parameters, 10 are either normalized or assigned values based on external data. $A$ and $A_{r}$ only affect the units in which output is measured, and are normalized to one. In the model, $\phi$ determines the share of employment in agriculture when subsistence consumption is asymptotically negligible in the case of positive productivity growth. In advanced countries, the share of employment in agriculture is below 2 percent; thus, we conservatively set $\phi=0.02$. We set the shares of labor and land in agricultural income to 0.6 and 0.4 . This implies $\gamma=0.75$ and $\theta=0.533$. We choose the curvature parameter of part-time labor supply $\nu$ to 0.6. Individuals that are 45 years of age and older are classified as old in the data. In 2004, this implies that 40.5 percent of our sample of village individuals are old, and we set $p_{o}=0.405$.

We choose $J=3$ to reflect the fact that the median village household has three working members in our sample. For the measures of township and urban households, we choose $N_{r}=0.328$ and $N_{u}=1.041$ to reflect non-agricultural employment that does not arise from village households. Appendix A.3 explains in detail how we determine these two statistics in the data. Note that the values of $N_{r}$ and $N_{u}$ are relatively unimportant for our analysis since township and urban families make no production decisions in our model.

There are 22 remaining parameters that are jointly determined by comparing model and data moments. Below, we discuss their identification.

Employment and value-added shares.-We use the following five moments for employment. Among village residents, the share of individuals working full-time in agriculture, either as agricultural workers or as farm operators, is 49.3 percent, which helps determine the value of the subsistence level of consumption $\bar{a}$ as in standard models of structural transformation. The shares of villagers that work part-time in both agriculture and nonagriculture, either rural or urban, are 16.0 and 5.3 percent, respectively, which help determine the value of the time fixed cost of part-time work, $c^{r}$ and $c^{u}$. The average number of days of labor supplied to agriculture among part-time workers, normalized by total labor days, is 
0.278, which is informative of the relative efficiency of labor supply in agriculture $(\kappa)$. The remaining 29.4 percent of workers are full-time rural (14.6 percent) and urban (14.8 percent) non-agricultural workers. Conditional on labor mobility barriers, the non-agricultural employment shares are informative of the productivity across the rural and urban sectors $\left(A_{r}\right.$ and $A_{u}$ ). Since we normalized $A_{r}=1$, the relative employment share is relevant for the value of $A_{u}$. Average ability of township and urban households $(\bar{h})$ affects the value-added share of the non-agricultural sector, hence we choose $\bar{h}$ such that, given the sectoral employment shares, the ratio of the average product of labor in agriculture and non-agriculture is 2.56.

Labor income.-For non-agricultural ability, we need to estimate two dispersion parameters, $\sigma_{h}^{H}$ and $\sigma_{h}^{I}$, which govern the family and individual components of ability. We choose two moments: first, the standard deviation of log wage income among full-time non-agricultural workers, which is 0.609; and second, for those households who have two full-time nonagricultural workers, we compute the rank correlation between their wage income, which is 0.556 . The correlation between the agricultural and non-agricultural ability, $\lambda$, is chosen to match the within-family correlation of non-agricultural wage income and farm profit of 0.082 .

We use two sectoral wage differentials, the difference between rural non-agricultural income and farm profit (0.182) and that between rural and urban non-agricultural wage income (0.156), to identify the level of labor mobility barriers: $\mu^{r}$ and $\mu^{u}$. Wage differentials reflect both labor mobility barriers and the relative productivity between sectors. Given that the relative productivity has been determined by the relative employment shares, wage differentials can then determine the level of labor mobility barriers.

Agricultural production.-We use three moments on agricultural production. The dispersion of farm TFP (0.662) is informative of agricultural ability dispersion, which is the sum of $\sigma_{s}^{H}$ and $\sigma_{s}^{I}$. These are not separately identified because for each family we only observe one operator in the data; hence, we assume that the household and individual components of ability are equally important, i.e., $\sigma_{s}^{H} / \sigma_{s}^{I}=\sigma_{h}^{H} / \sigma_{h}^{I}$. The dispersion of farm TFPR, which is 
0.635, and the correlation between farm TFP and farm TFPR, which is 0.967 , jointly determine the parameters of idiosyncratic agricultural distortions, $\sigma_{\varepsilon}$ and $\zeta$. In order to estimate more robust measures of farm TFP and farm distortions from the data, we exploit the panel dimension of the data following Adamopoulos et al. (2021) by estimating household fixed effects that are less susceptible to measurement error.

Cohort differences.-We use five moments from the cohort differences between young and old individuals. The difference in log farming profit between young and old operators is 0.054, which helps determine $\mu_{s}^{y}$, the young-old agricultural productivity ratio. In the urban (rural) non-agricultural sector, the log wage income difference is $-0.161(-0.056)$, with old individuals having on average higher wage income. The young-old wage differential is a product of differences in ability and labor mobility barriers. To disentangle these sources, we target the employment shares by cohorts, in particular the fact that the old cohort is much more likely to be engaged in agriculture. Among all workers with at least some urban non-agricultural income, only 10.9 percent are old, while among farm operators and full-time agricultural workers, 54.8 percent are old. Among the remaining workers with at least some rural non-agricultural income, 36.9 percent are old. With these moments (two on wage differentials and two on young-old employment shares), we separately identify four parameters: the young-old non-agricultural ability drift $\mu_{h}^{y}$, the young-old labor mobility barriers drifts $\mu_{o}^{r}$ and $\mu_{o}^{u}$, and the dispersion in labor mobility barriers $\sigma_{\xi}$.

While young-old gaps in ability and labor mobility barriers drive wage differentials in the same direction, they affect employment shares differently, and hence can be separately identified. In particular, although old cohorts on average have higher wage income in the nonagricultural sector, the estimated ability is higher for the young cohorts (with $\mu_{h}^{y}=0.234$ ). The reason that old cohorts have higher wage income is exactly because they face substantially higher labor mobility barriers, especially when entering the urban non-agricultural sector $\left(\mu_{o}^{r}=1.301\right.$ and $\left.\mu_{o}^{u}=1.409\right)$. As a result, among the old cohort, only the most productive choose to work in non-agriculture, pushing up the observed wage income. 
Similarly, in the identification of the dispersion of the labor mobility barrier, $\sigma_{\xi}$, we simultaneously observe that (1) old individuals face higher barriers when entering the urban non-agricultural sector than when entering the rural non-agricultural sector, and (2) more old individuals work in the rural than the urban non-agricultural sector. The identification of $\sigma_{\xi}$ then arises from the elasticity between these observations. Intuitively, if $\sigma_{\xi}=0$, then in equilibrium all old individuals prefer the rural than the urban non-agricultural sector due to lower barriers, while all young individuals prefer the urban sector. In contrast, if $\sigma_{\xi}$ is infinitely large, then the sector choice is purely idiosyncratic, independent of young or old. Since the sorting pattern we observe is in between these extreme cases, the data provides information on the size of $\sigma_{\xi}$.

Land insecurity.-We use two moments to determine the level and dispersion of the land income loss $b_{i}$. First, among village households, 71.9 percent operate farms which helps determine $\mu_{b}$. Second, the average wage income in the non-agricultural sector for families not operating a farm is 28.2 percent higher than for families with farm operators, which helps determine $\sigma_{b}$. To illustrate why the wage ratio moment is informative, consider the following two cases. If $\sigma_{b}=0$, i.e., $b_{i}=\mu_{b}$ for every family, families with higher nonagricultural ability (correlated within families) are more likely to surrender farm land and specialize in non-agriculture, resulting in a large average non-agricultural wage ratio between farming and non-farming families. On the other hand, if $\sigma_{b}$ is infinitely large, the decision of surrendering land depends mostly on the realization of $b_{i}$ rather than ability, generating a small average wage ratio. Hence, other things equal, the wage ratio moment in the data helps identify $\sigma_{b}$.

In identifying the level of $b_{i}$, it is crucial that we allow for within-family correlation of non-agricultural abilities. Specifically, an unproductive farm may exist because of concerns on land insecurity $\left(b_{i}\right)$ or because the non-agricultural ability of the operator is low. Once we know other family members' non-agricultural abilities, we have a conditional expectation of the operator's non-agricultural ability and thus the likelihood that this unproductive farm 
exists because of concerns on land insecurity.

All the data moments are calculated using 2004, except those related to farm TFP and farm distortions for which we use the entire panel to estimate household fixed effects. The estimated parameter values are displayed in Table B.3.

\section{On Labor Mobility Barriers}

In our baseline estimation for 2004, labor mobility barriers are higher for the rural nonagricultural sector than the urban non-agricultural sector $\left(\mu_{r}=0.959, \mu_{r}^{o}=1.301\right.$, and $\left.\mu_{u}=0.400, \mu_{u}^{o}=1.409\right)$. This result is slightly counter intuitive, as one would probably expect the opposite - rural non-agricultural sector should be geographically closer to village households and the barriers might have been lower. In this section, we first show that this result is not driven by observed worker heterogeneity that we do not explicitly model. We then discuss potential explanations for it.

We start by noting that this result is directly related to the fact that the calculated daily wage is higher in the rural non-agricultural sector than in the urban non-agricultural sector for the early years (up to 2011). We then assess if this can be explained by any observed characteristics that we do not explicitly model. We consider a Mincer regression of log daily wage on a dummy variable which equals to one if an individual works in the rural nonagricultural sector (versus the urban one) and controls for measures of self-reported health, years of education, gender, hukou status, and the industry code, for each year in our sample. We still find that the coefficient of rural dummy to be positive and significant for the early years. This suggests that the higher wage rate in the rural non-agricultural sector is not driven by worker characteristics that we observe in the data but are not explicitly modeled. In fact, even when we control for individual fixed effects in a panel regression, the coefficients for rural-year dummies are still positive and significant for early years albeit slightly smaller in magnitudes. 
Table B.3: Model Parameters and Values

\begin{tabular}{|c|c|c|}
\hline Parameter & Value & Description \\
\hline \multicolumn{3}{|c|}{ Productivity: } \\
\hline$A$ & 1 & TFP of the agricultural sector (normalized) \\
\hline$A_{r}$ & 1 & TFP of the rural non-agricultural sector (normalized) \\
\hline$A_{u}$ & 0.750 & TFP of the urban non-agricultural sector \\
\hline $\bar{h}$ & 3.735 & Average ability township and urban households \\
\hline \multicolumn{3}{|c|}{ Technologies: } \\
\hline$\gamma$ & 0.75 & Span-of-control in the agricultural sector \\
\hline$\theta$ & 0.533 & Land income share in the agricultural sector \\
\hline \multicolumn{3}{|c|}{ Labor Supply: } \\
\hline$\nu$ & 0.60 & Curvature of labor supply in agriculture \\
\hline$\kappa$ & 1.036 & Relative efficiency of labor supply in agriculture \\
\hline$c^{r}$ & 0.061 & Time cost of part-time working in rural non-agriculture \\
\hline$c^{u}$ & 0.102 & Time cost of part-time working in urban non-agriculture \\
\hline \multicolumn{3}{|c|}{ Preferences: } \\
\hline $\bar{a}$ & 0.219 & Subsistence consumption of agricultural good \\
\hline$\phi$ & 0.02 & Long-run agricultural employment share \\
\hline \multicolumn{3}{|c|}{ Endowments: } \\
\hline$J$ & 3 & Number of individuals per village household \\
\hline$N_{r}$ & 0.328 & Measure of township households \\
\hline$N_{u}$ & 1.041 & Measure of urban households \\
\hline$p_{o}$ & 0.405 & Fraction of old cohorts among village individuals \\
\hline \multicolumn{3}{|c|}{ Ability Distribution: } \\
\hline$\lambda$ & 0.289 & Correlation between two-dimensional abilities \\
\hline$\sigma_{s}^{H}$ & 0.594 & Household fixed effect of agricultural ability \\
\hline$\sigma_{s}^{I}$ & 0.286 & Individual fixed effect of agricultural ability \\
\hline$\sigma_{h}^{H}$ & 0.742 & Household fixed effect of non-agricultural ability \\
\hline$\sigma_{h}^{n}$ & 0.358 & Individual fixed effect of non-agricultural ability \\
\hline$\mu_{s}^{y}$ & 0.105 & Young cohort effect of agricultural ability \\
\hline$\mu_{h}^{y}$ & 0.234 & Young cohort effect of non-agricultural ability \\
\hline \multicolumn{3}{|l|}{ Distortions: } \\
\hline$\zeta$ & -0.930 & Correlated component of idiosyncratic farm distortions \\
\hline$\sigma_{\epsilon}$ & 0.164 & Random component of idiosyncratic farm distortions \\
\hline$\mu_{r}$ & 0.959 & Mean labor mobility barrier for rural non-agriculture \\
\hline$\mu_{u}$ & 0.400 & Mean labor mobility barrier for urban non-agriculture \\
\hline$\mu_{r}^{o}$ & 1.301 & Drift (old) of labor mobility barrier for rural non-agriculture \\
\hline$\mu_{u}^{o}$ & 1.409 & Drift (old) of labor mobility barrier for urban non-agriculture \\
\hline$\sigma_{\xi}$ & 0.609 & Dispersion of labor mobility barrier \\
\hline$\mu_{b}$ & -1.577 & Mean cost of land loss if not farming \\
\hline$\sigma_{b}$ & 0.801 & Dispersion land loss cost \\
\hline
\end{tabular}

Notes: List of parameters and calibrated values. A set of 10 parameters: $p_{o}, \phi, \gamma, \theta, \nu, A, A_{r}, J, N_{r}$, and $N_{u}$, are either normalized or directly assigned values from outside evidence. The remaining 22 parameters are jointly determined by comparing model moments and targeted data moments. 
When we control for age, the coefficient on the rural dummy is slightly reduced in magnitude in the Mincer regression. This is because the young cohorts are much more likely to work in the urban non-agricultural sector while the old cohorts are more likely to work in the rural non-agricultural sector, and hence the Mincer regression attributes the rural-urban wage differences to young-old wage differences. In other words, the Mincer regression implies that, as an individual gets older, she earns a higher wage and is more likely to work in the rural non-agricultural sector, ceteris paribus. Importantly, in our model, we also explicitly allow for young and old cohort differences and hence we do explicitly model this age dimension. In our baseline estimation, however, our model-based identification does not directly attribute this rural-urban wage differences to young-old wage differences. We now briefly explain the intuition.

In our identification, we target two moments on young-old wage differences, i.e., young-old wage differences in the rural non-agricultural sector and that in the urban non-agricultural sector. In calculating these moments, we find that old cohorts have on average higher wage rates than young cohorts with each sector for the year 2004. In our model, a higher wage rate for old cohorts may be due to higher ability of old cohorts, or may be due to selection effects driven by higher labor mobility barriers faced by the old cohorts. We separately identify these two by further using the employment data. Particularly, if higher wage rate for old cohorts is due to their higher non-agricultural ability, then we should observe that old cohorts are more likely to work in the non-agricultural sectors while young cohorts are more likely to work in the agricultural sector. This is inconsistent with the data. Hence, the fact that fewer old individuals work in the non-agricultural sectors implies that their higher wage rates are driven by selection, which is in turn driven by higher labor mobility barriers. In fact, our baseline estimation indicates that the old cohorts have on average lower non-agricultural ability $\left(\mu_{h}^{y}=0.234\right)$. A a result, the fact that the rural non-agricultural sector, in which old individuals are more likely to work, has a higher wage rate cannot be explained by higher worker ability. Higher labor mobility barriers are needed to reconcile. 
To summarize, the results from our model-based identification differ from the Mincer regression, mainly because the model uses data on both young-old wage differentials and young-old employment shares to disentangle the source of rural-urban wage differences. By contrast, the Mincer regression does not utilize any information from employment shares and thus attributes some of the rural-urban wage differences to young-old wage differentials, without properly accounting for selection driven by labor mobility barriers. Noteworthy, even after controlling for age, the Mincer regression still finds significant, however smaller coefficients for the rural dummy in early years.

We also note that the labor mobility barriers are higher in the rural non-agricultural sector only for the baseline estimation for 2004, and reversed in our 2018 estimation. The differences are also larger for the young cohorts than for the old cohorts. In addition, when we allow for regional heterogeneity, this result only applies to Remote areas, while in Periurban areas we find labor mobility barriers to be lower in the rural non-agricultural sector than in the urban non-agricultural sector.

There are several possible reasons why labor mobility barriers might be higher for the rural non-agricultural sector. First, the urban non-agricultural sector provides more nonpecuniary benefits, increasing workers' willingness to work in the urban non-agricultural sector at a lower wage rate. These non-pecuniary benefits include better life-cycle earning growth due to learning-by-doing and human capital externalities in the urban sector (Glaeser and $\mathrm{Lu}, 2018$ ). This is consistent with our estimation result of the lower urban labor mobility barriers, especially for the young cohorts who care more about the life-cycle growth potentials. Second, working in the urban sector may also provide opportunities of obtaining urban hukou which is valuable in its own right (Wu and You, 2020). These non-pecuniary benefits may effectively reduce the labor mobility barriers associated with the urban non-agricultural sector.

When we allow for regional heterogeneity, we find that it is only in Remote areas that non-agricultural labor mobility barriers are higher in rural than in urban areas. Our baseline 
estimation using nationwide observations likely reflects the dominant weight of the Remote observations. This suggests that higher labor mobility barriers to the rural non-agricultural sector could be tied to larger labor market imperfections in remote rural areas. We also cannot totally rule out measurement issues in the survey, and the possibility that individuals interviewed in remote areas have less accurate information on urban earnings of family members compared to peri-urban areas.

\section{Alternative Calibrations}

We start by describing how we re-calibrate the economy to 2018 moments as in Section 6.2.

In 2018, $N_{r}$ and $N_{u}$ are 1.55 and 2.87, respectively. Details are in Appendix A.3. We choose $\bar{h}$ to match the nominal labor productivity gap between agriculture and nonagriculture of 2.18. $p_{o}=52.4 \%$ to reflect the fraction of old agents in 2018. Other relevant moments are calculated from our 2018 wave of micro data. We list parameter values in the first column of Table D.4.

The second column of Table D.4 lists parameter values for the alternative calibration in Section 7.1 where $\mu_{b}$ is chosen to match an exogenous $b_{i} / I_{i}$ ratio while other parameters are determined in the same way. The third and fourth columns list parameter values for the experiment in Section 7.2 for the suburban and remote regions, respectively. 
Table D.4: Parameter Values for Various Alternative Calibrations

\begin{tabular}{|c|c|c|c|c|}
\hline \multirow[t]{2}{*}{ Parameters } & \multicolumn{4}{|c|}{ Calibrations } \\
\hline & 2018 Moments & Alternative $\mu_{b}$ & Peri-urban & Remote \\
\hline \multicolumn{5}{|c|}{ Productivity: } \\
\hline$A$ & 1 & 1 & 1 & 1 \\
\hline$A_{r}$ & 1 & 1 & 1 & 1 \\
\hline$A_{u}$ & 1.028 & 0.746 & 0.800 & 0.783 \\
\hline $\bar{h}$ & 0.610 & 3.673 & 2.215 & 4.375 \\
\hline \multicolumn{5}{|c|}{ Technologies: } \\
\hline$\gamma$ & 0.75 & 0.75 & 0.75 & 0.75 \\
\hline$\theta$ & 0.533 & 0.533 & 0.533 & 0.533 \\
\hline \multicolumn{5}{|c|}{ Labor Supply: } \\
\hline$\nu$ & 0.60 & 0.60 & 0.60 & 0.60 \\
\hline$\kappa$ & 0.887 & 1.035 & 0.995 & 1.038 \\
\hline$c^{r}$ & 0.051 & 0.060 & 0.057 & 0.062 \\
\hline$c^{u}$ & 0.069 & 0.105 & 0.069 & 0.107 \\
\hline \multicolumn{5}{|l|}{ Preferences: } \\
\hline $\bar{a}$ & 0.071 & 0.220 & 0.193 & 0.245 \\
\hline$\phi$ & 0.02 & 0.02 & 0.02 & 0.02 \\
\hline \multicolumn{5}{|c|}{ Endowments: } \\
\hline$J$ & 3 & 3 & 3 & 3 \\
\hline$N_{r}$ & 1.043 & 0.328 & 0.328 & 0.328 \\
\hline$N_{u}$ & 3.167 & 1.041 & 1.041 & 1.041 \\
\hline$p_{o}$ & 0.524 & 0.405 & 0.415 & 0.403 \\
\hline \multicolumn{5}{|c|}{ Ability Distribution: } \\
\hline$\lambda$ & 0.210 & 0.251 & 0.099 & 0.362 \\
\hline$\sigma_{s}^{H}$ & 0.583 & 0.598 & 0.514 & 0.600 \\
\hline$\sigma_{s}^{I}$ & 0.493 & 0.292 & 0.254 & 0.292 \\
\hline $\begin{array}{l}\sigma_{s} \\
\sigma_{h}^{H}\end{array}$ & 0.512 & 0.736 & 0.801 & 0.756 \\
\hline$\sigma_{h}^{n}$ & 0.434 & 0.359 & 0.396 & 0.369 \\
\hline$\mu_{s}^{y}$ & 0.208 & 0.088 & 0.064 & 0.143 \\
\hline$\mu_{h}^{y}$ & 0.231 & 0.220 & 0.265 & 0.298 \\
\hline \multicolumn{5}{|l|}{ Distortions: } \\
\hline$\zeta$ & -0.952 & -0.925 & -0.898 & -0.918 \\
\hline$\sigma_{\varepsilon}$ & 0.219 & 0.167 & 0.174 & 0.155 \\
\hline$\mu_{r}$ & 0.682 & 1.030 & 0.510 & 0.852 \\
\hline$\mu_{u}$ & 0.687 & 0.461 & 0.491 & 0.307 \\
\hline$\mu_{r}^{o}$ & 1.096 & 1.391 & 0.862 & 1.156 \\
\hline$\mu_{u}^{o}$ & 1.251 & 1.530 & 1.425 & 1.124 \\
\hline$\sigma_{\xi}$ & 0.340 & 0.678 & 0.551 & 0.373 \\
\hline$\mu_{b}$ & -2.901 & -1.659 & -2.067 & -1.322 \\
\hline$\sigma_{b}$ & 1.751 & 0.798 & 0.611 & 1.242 \\
\hline
\end{tabular}

Notes: Parameter values for alternative calibrations. A set of 10 parameters: $p_{o}, \phi, \gamma, \theta, \nu, A, A_{r}, J, N_{r}$, and $N_{u}$, are either normalized or directly assigned values from outside evidence. The remaining 21 parameters are jointly determined by comparing moments between the model and targeted data. The first column lists calibrated parameter values for the year 2018. The second column lists parameter values for an alternative calibration of $\mu_{b}$, chosen to match an exogenous $b_{i} / I_{i}$ ratio. The third and fourth columns list parameter values for the regional calibrations of Peri-urban and remote regions. 